\title{
X-33 Reusable Launch Vehicle Demonstrator, Spaceport and Range
}

\author{
Gary Letchworth ${ }^{1}$ \\ NASA Kennedy Space Center, Florida 32899
}

\begin{abstract}
The X-33 was a suborbital reusable spaceplane demonstrator, in development from 1996 to early 2001. The intent of the demonstrator was to lower the risk of building and operating a full-scale reusable vehicle fleet. Reusable spaceplanes offered the potential to lower the cost of access to space by an order of magnitude, compared with conventional expendable launch vehicles. Although a cryogenic tank failure during testing ultimately led to the end of the effort, the X-33 team celebrated many successes during the development. This paper summarizes some of the accomplishments and milestones of this $\mathrm{X}$-vehicle program, from the perspective of an engineer who was a member of the team throughout the development. X-33 Program accomplishments include rapid, flight hardware design, subsystem testing and fabrication, aerospike engine development and testing, Flight Operations Center and Operations Control Center ground systems design and construction, rapid Environmental Impact Statement NEPA process approval, Range development and flight plan approval for test flights, and full-scale system concept design and refinement. Lessons from the X-33 Program may have potential application to new RLV and other aerospace systems being developed a decade later.
\end{abstract}

\section{Nomenclature}

$\begin{array}{ll}\text { AFFTC } & =\text { Air Force Flight Test Center } \\ C A N & =\text { Cooperative Agreement Notice } \\ \text { CDR } & =\text { Critical Design Review } \\ \text { EIS } & =\text { Environmental Impact Statement } \\ \text { FOC } & =\text { Flight Operations Center } \\ \text { LEO } & =\text { Low Earth Orbit } \\ \text { LO2 } & =\text { Liquid Oxygen } \\ \text { LH2 } & =\text { Liquid Hydrogen } \\ \text { OCC } & =\text { Operations Control Center } \\ \text { PDR } & =\text { Preliminary Design Review } \\ \text { RLV } & =\text { Reusable Launch Vehicle } \\ \text { SLI } & =\text { Space Launch Initiative } \\ \text { SSTO } & =\text { Single Stage to Orbit } \\ \text { STA } & =\text { Structural Test Article } \\ T P S & =\text { Thermal Protection System }\end{array}$

\section{Introduction}

$\mathrm{T}$

HE X-33 Phase 2 demonstrator development began in July 1996 when NASA awarded a Lockheed Martin Skunkworks team with a Cooperative Agreement, NCC8-115. Competitors included McDonnell Douglas and Rockwell International. The X-33 was intended to be a half-scale, suborbital demonstrator for a full scale reusable launch vehicle (RLV) spaceplane. Although a cryogenic tank failure during testing ultimately led to the end of the effort, the X-33 team celebrated many successes during the development. This paper summarizes some of the accomplishments and timeline of this X-vehicle effort between 1996 and 2001. X-33 Demonstrator Program accomplishments include rapid flight hardware design, subsystem testing and fabrication, Flight Operations Center and Operations Control Center ground systems design and construction, aerospike engine development and testing, rapid Environmental Impact Statement NEPA process approval, and Range development and flight plan approval for

\footnotetext{
${ }^{1}$ Chief, $21^{\text {st }}$ Century Ground Systems Program, Flight Systems \& Operations Integration Division, Spacecraft Branch, Mailstop LX-O1, AIAA Member.
} 
test flights to Dugway, Utah and Malmstrom AFB, Montana. Lessons from the X-33 development may have potential application a decade later to new RLV and other launch system concepts that are being studied and developed.

\section{X-33 Objectives and Milestones}

This section overviews the original objectives of the X-33 Program and summarizes the milestones achieved during the development effort.

\section{A. Original X-33 Objectives}

The X-33 team defined, and pursued meeting, several objectives during the Cooperative Agreement. The first objective was to reduce the risk of building and operating a fullscale RLV fleet, called VentureStar $^{\mathrm{TM}}$, by building and testing a $53 \%$ scale suborbital demonstrator (Figure $1)$.

The second objective was to validate the design tools and processes. The third objective of X-33 was to validate the lifting body characteristics, linear aerospike engine

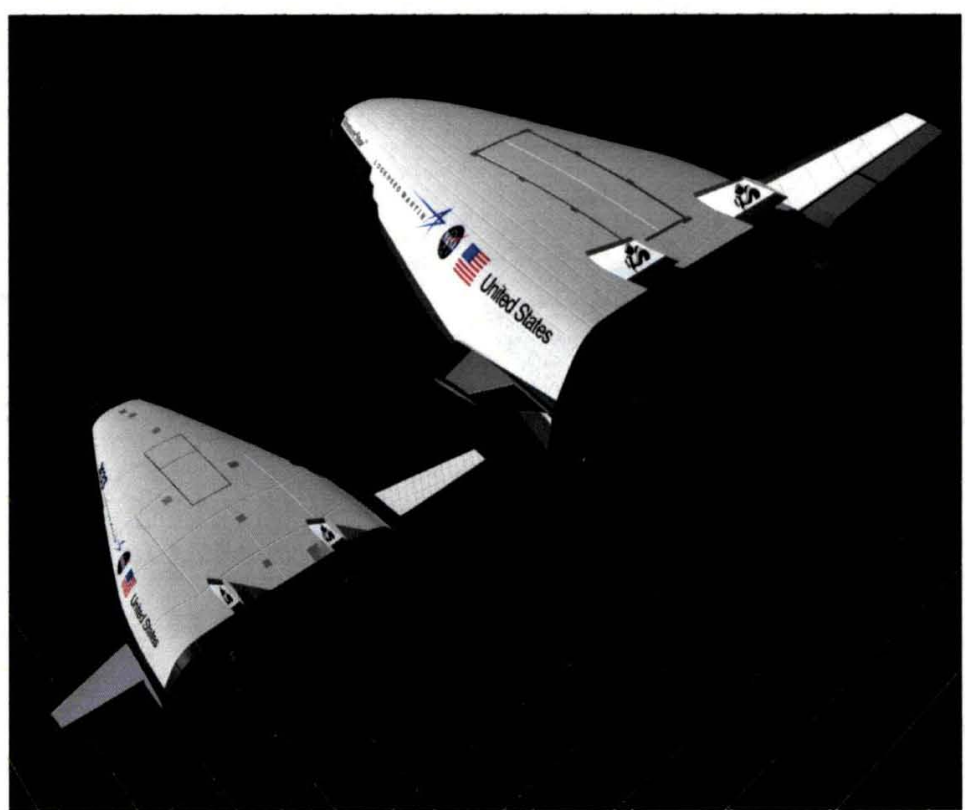

Figure 1. X-33 was a $53 \%$ scale demonstrator for the VentureStar ${ }^{\mathrm{TM}} \mathrm{RLV}$ operational vehicle. integration and aerothermal effects of the integrated vehicle. The final objective was to demonstrate RLV technologies in a realistic flight environment. Technologies to be demonstrated on the X-33 included reusable cryogenic tankage, composite structures, durable reusable TPS, advanced avionics, autonomous flight operations, reliable non-toxic propulsion and aircraft-like operations.

The vehicle was intended to launch like a rocket, yet fly and be operated like an airplane. The long term goal was to increase vehicle reliability and enable an order of magnitude reduction in the cost of delivering payloads to and from LEO. The goal was to reduce the payload delivery cost from $\$ 10,000$ per pound to $\$ 1000$ per pound.

\section{B. X-33 Program Milestones}

The X-33 Phase 2 CAN had the goal of achieving a rapid development schedule. The X-33 milestones ${ }^{1}$ included the following: The Cooperative Agreement was awarded July 1996, in an announcement by Vice President $\mathrm{Al}$ Gore. The team included prime contractor Lockheed Martin Skunk Works, Palmdale, CA; Rocketdyne (Boeing Rocketdyne), Canoga Park, CA; Rohr (B.F. Goodrich), Chula Vista, CA; and AlliedSignal Aerospace, Teterboro, NJ. The Preliminary Design Reviews for the flight and ground systems occurred between November and December, 1996 - only four months after award. Critical Design Review was held October 1997, only 10 months after PDR.

Groundbreaking at the "Spaceport", called the Flight Operations Center, occurred November 1997, most of the major launch site construction was completed in December 1998, and this Center was dedicated only 16 months after groundbreaking, March 1999. The vehicle LO2 cryogenic tank arrived in Palmdale, February 1998. Linear aerospike engine-related testing began at Stennis Space Center, October 1998.

The LH2 composite tanks were completed August 1999. Unfortunately, the one of the LH2 tanks failed in the MSFC test stand November, 1999, during the $5^{\text {th }}$ in a series of cryogenic and structural load tests. Lockheed Martin proceeded with design of an alternate aluminum lithium metallic tank design by December. By September 2000, $95 \%$ of X-33 components were fabricated, tested and delivered, and the vehicle assembly was $75 \%$ complete. Dual linear aerospike engine testing began at Stennis, December 2000.

The X-33 team estimated an approximate 18 month schedule slip, and required additional funds for the LH2 tank recovery. The team solicited, but not awarded, funds as part of NASA's emerging SLI Program. As a result, the X33 Program Cooperative Agreement came to a completion, March 2001. 


\section{X-33 Flight Vehicle Configuration and Subsystems}

This section provides an overview of the $\mathrm{X}$ 33 flight vehicle configuration, subsystems descriptions and test accomplishments.

\section{A. X-33 Vehicle Configuration}

Figure 2 provides views of the X-33 outer moldline. The X-33 is a lifting body shape, which provides advantageous $\mathrm{L} / \mathrm{D}$ for crossrange and maneuvering. The vehicle is powered during ascent by two modified J-2S engines, called XRS-2200, delivering 410,000 lb thrust at liftoff. The engines are configured as linear aerospikes, and provide actuator-free thrust vectoring by differential throttling of each of the two banks of the engines. The vehicle uses $\mathrm{LO} 2$ and $\mathrm{LH} 2$ for propellants, with a load of $30,000 \mathrm{lb} \mathrm{LH} 2$ and $180,000 \mathrm{lb} \mathrm{LO} 2$. The vehicle is $69 \mathrm{ft}$. long and $77 \mathrm{ft}$ wide. The X-33 GLOW is $285,000 \mathrm{lb}$, and the vehicle can obtain a maximum speed of Mach 13.8. The vehicle uses metallic TPS on the windward side, AFRSI and FRSI thermal blankets on the leeward side, and carbon-carbon on the nosecap and leading edges.

Figure 3 illustrates the major propulsion and flight control components of the vehicle. X-33 utilizes two multi-lobe $\mathrm{LH} 2$ tanks in the aft, and a single multi-lobe LO2 tank in the forward section. An avionics bay is located on the leeward side and provides single level deep LRU accessibility. Two vertical stabilizers provide yaw control, and two body flaps and two canted horizontal stabilizers with inboard and outboard elevons provide pitch, roll and supplemental yaw control. T-0 umbilicals provide ground interfaces for propellants, pressurants, command and electrical services.

\section{B. Thermal Protection System}

The X-33 is protected from high heating on its windward surface by 1241 durable, metallic inconel TPS panels, which are mechanically attached to the vehicle using a standoff support structure. B.F. Goodrich designed and built the thermal panels (Figure 4). Flexible thermal blankets, similar to those used on the Space Shuttle, are used on leeward surfaces where heating rates are lower, and carbon-carbon is used on the nosecap and aerosurface leading edges.

NASA DFRC performed supersonic testing of the TPS panels, AFRSI and seals during six flights in 1998, using an F-15B (Figure 4). The
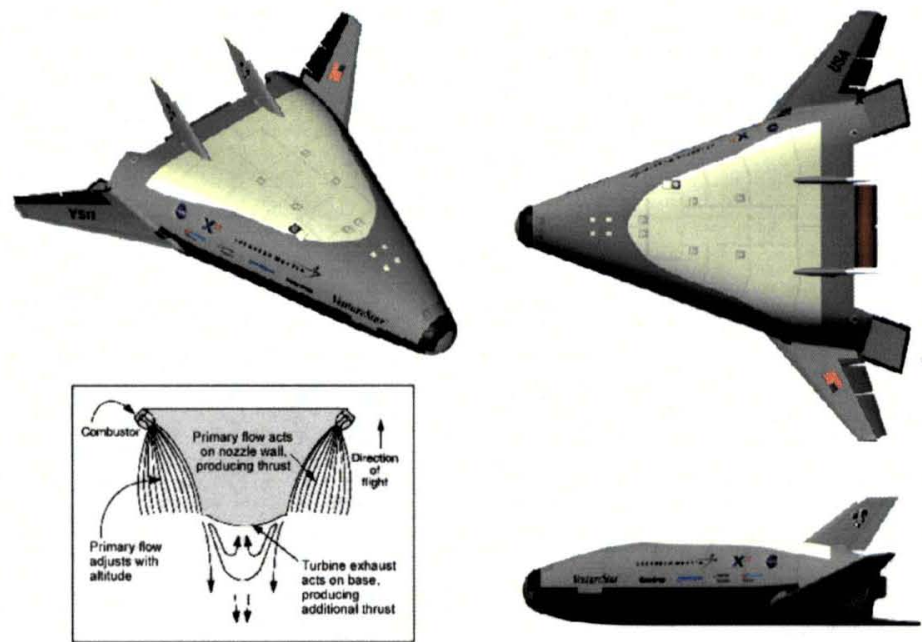

Figure 2. X-33 Vehicle Configuration and Aerospike Engine

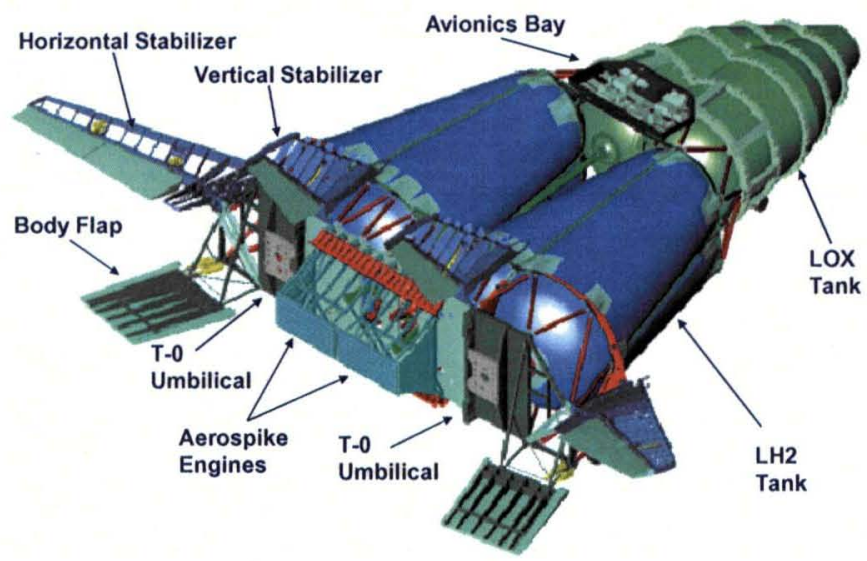

Figure 3. X-33 Vehicle Isometric Cutaway
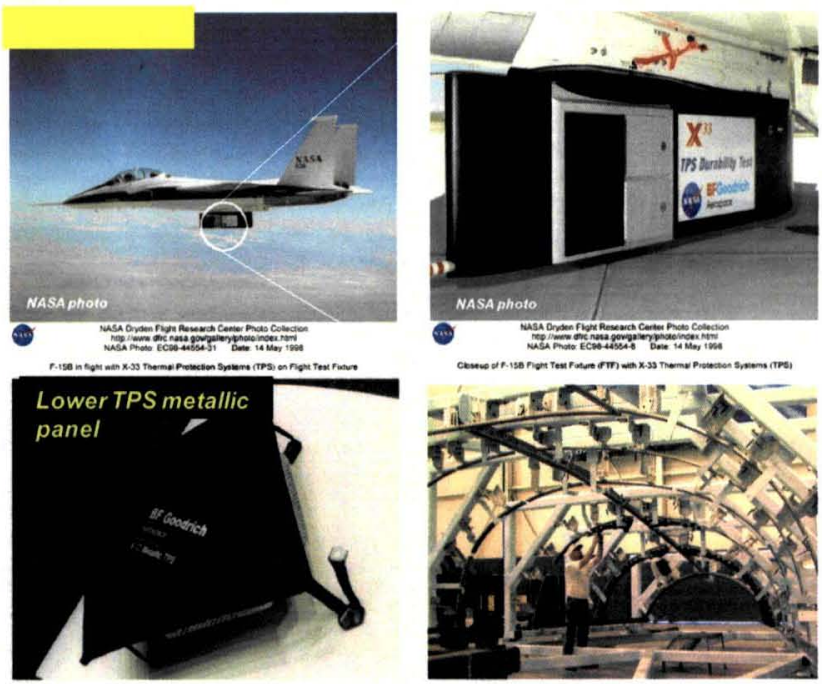

Figure 4. X-33 TPS Panel and Flight Tests 
flights tested the durability of the materials at hypersonic velocities. A nine panel TPS array, complete with secondary seals, was test-fitted on the vehicle during assembly in September 1998. Removal and replacement of the panels was also demonstrated at the time. The first upper TPS panels arrived in October 1998 for installation on the forward LO2 tank area. Other major testing by B.F. Goodrich was completed at MSFC during the same month. By October $1999,52 \%$ of the 1241 panels had been manufactured and delivered to the Palmdale assembly plant.

\section{Linear Aerospike Engine}

The X-33 utilizes two linear aerospike engines, using $\mathrm{LO} 2 / \mathrm{LH} 2$ cryogenic propellants. BoeingRocketdyne developed the engines, designated XRS- $2200^{2}$. The engines, shown in Figure 5, use a series of 10 external combustor nozzles (thrust cells), arrayed on each side of two ramps to deliver thrust. The nozzles are truncated; turbine exhaust is delivered out of the base, producing additional thrust.

One advantage of the aerospike is that they automatically compensate for altitude, delivering efficient thrust (i.e., the nozzles are not under or overexpanded like conventional bell nozzle engines). Another advantage is that pitch, roll and yaw can be achieved from the two engines using differential throttling. This avoids the complexity and mass of gimbals, bellow feed lines and actuators. The turbomachinery power packs can

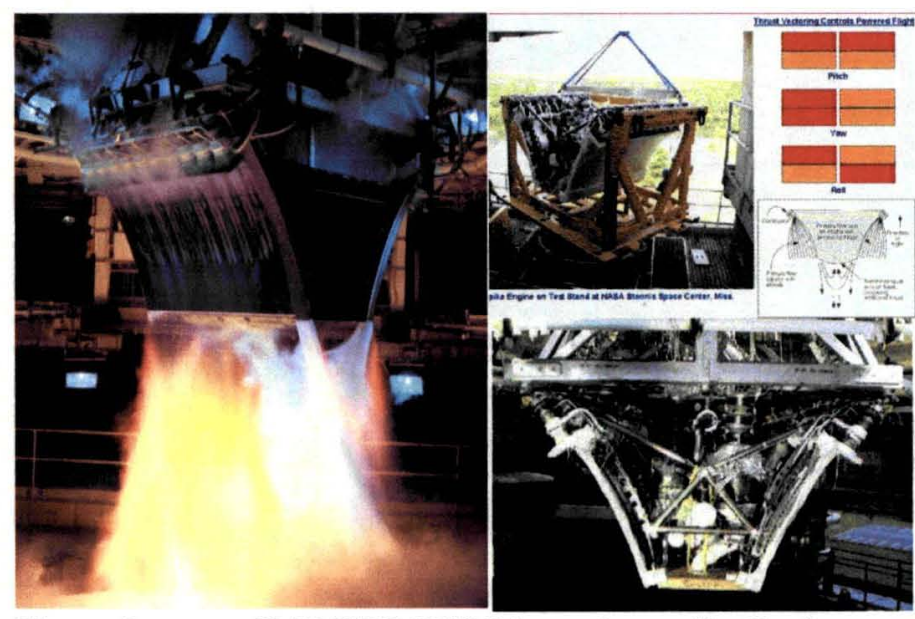

Figure 5. X-33 XRS-2200 Linear Aerospike Engine operate in single "engine-out" mode, and feed to both sets of ramps, maximizing abort capability.

Finally, point loads are avoided by integrating the engines with the airframe, minimizing mass. The specific impulse of the engines is 340.3 seconds at sea level, and 429.3 seconds at vacuum.

Extensive testing was successfully performed on the aerospike engine components during the program, including thrusters, multi-cells, powerpack machinery, single and tandem engine testing. The first engine was delivered to Stennis Space Center July 1999 to begin testing, and tandem engine testing was initiated December 2000. Two of the nine tandem engine tests were completed prior to completion of the CAN in March 2001.

\section{LO2 Tank}

The LO2 tank was designed and built by Lockheed Martin Michoud Space Systems. Two LO2 tanks, shown in Figure 6, were built, and were comprised of lightweight aluminum lithium material. The first tank served as the structural test article (STA), and the second tank served as the flight test article. The STA tank was successfully tested at MSFC, May 1999, and the flight tank are and was delivered by an Airbus A300-600ST. The design, manufacturing, and proof testing of the flight LO2 tank was completed in only 19 months to meet the vehicle assembly schedule.

\section{E. LH2 Tank and Other X-33 Composites}

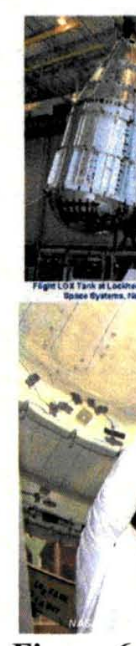

Figure 6 . Two tanks designed and built by
LM Michoud Space Systems

- Al-Li material

- Structural Test Article (STA) successful test at MSFC, May 1999

Flight Article arrived Palmdale Feb. 1998



X-33 LO2 Tanks at MSFC and Palmdale, CA

Composites were used extensively in the X-33

to lower the vehicle mass (Figure 7). Two LH2 tanks were constructed of composite graphite epoxy material. Each tank weighs $4,600 \mathrm{lb}$ and is designed to carry 29,000 gallons of LH2 at -423 degrees F. Alliant Techsystems in Clearfield, Utah, fabricated the composites for the tanks.

A joint Lockheed Martin-Alliant team assembled the tanks in a large autoclave at Lockheed Martin Missiles and Space, Sunnyvale, CA. Tank \#1 (Figure 7), was delivered from Sunnyvale to the Skunk Works plant in Palmdale, 
CA, October 1999. Tank \#2, shown in Figure 8, was delivered to MSFC for cryogenic and structural load testing. Tank \#2 was damaged during a cryogenic test.

In November 1999, a joint NASA-Lockheed Martin investigation team reported that the damage debonding, was caused by microcracks in the composite inner and outer skins. The cracks allowed pressurized hydrogen to seep into the core from inside the tank and caused the nitrogen gas maintained outside the tank as a safety measure to be "cryopumped" in through the outer skin as the liquid hydrogen chilled it. That produced pressure that was higher than expected in the composite core, which in turn caused the separation.

Composites were also used in other major components of the X-33 vehicle, including the aft structure, where the loads from the aerospike engines were distributed to the vehicle, and the upper TPS panel structure, where TPS interfaced with the propellant tanks.

\section{F. Other X-33 Subsystems}

$\mathrm{X}-33$ developed and tested non-toxic gaseous oxygen and methane systems and thrusters for reaction control. The F-16 nosewheel assembly was used for the nosegear. The avionics featured one level deep component access capability, by placing major components in an avionics bay located aft of the LO2 tank. NASA and LM developed vehicle health monitoring health nodes. LM Sanders provided the first two health nodes November 1998, and initial vehicle power-up testing occurred December 1999. Other components that were designed, built and delivered for vehicle assembly at Palmdale included the body flaps, vertical stabilizers and canted fins. By September 2000, $95 \%$ of X-33 components were fabricated, tested and delivered, and the vehicle assembly was $75 \%$ complete.
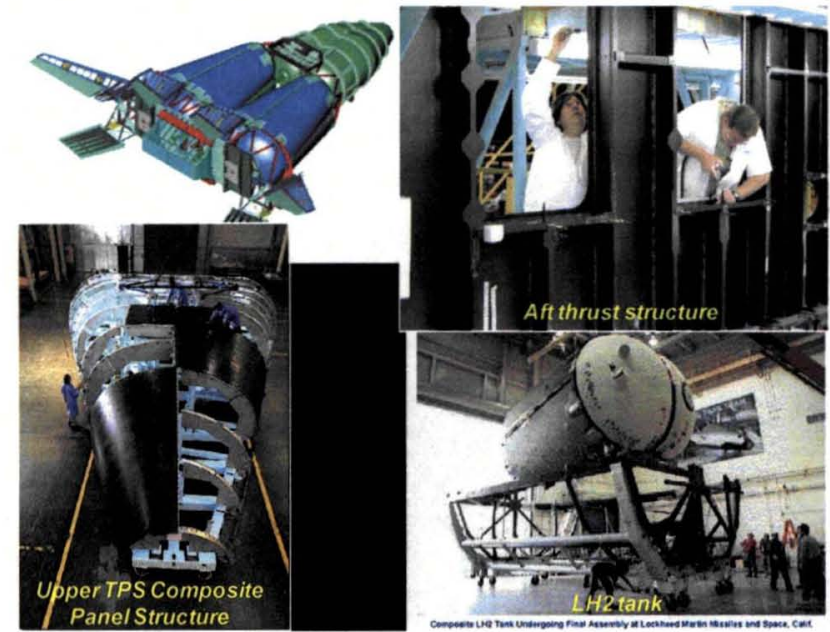

Figure 7. X-33 Composites: LH2 Tank and Structures

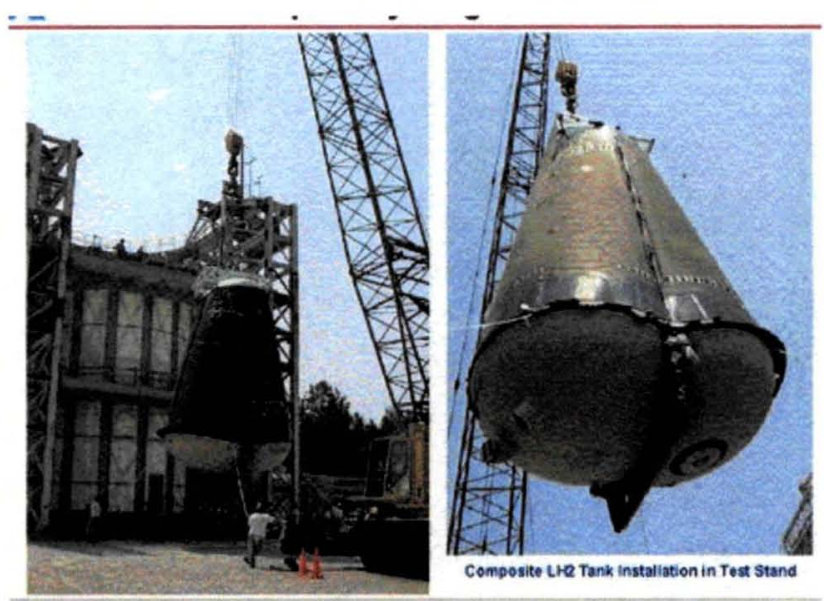

Figure 8. X-33 LH2 Tank Testing at MSFC

\section{Operations Concept and Flight Test Profile}

This section describes the concept for operating the X-33 reusable launch vehicle, and the flight test profiles that were initially planned for the vehicle.

\section{A. X-33 Operations Concept}

The X-33 vehicle was intended to demonstrate, as much as practical, the cost-effective operations of a fullscale reusable spaceplane. The concept was for the vehicle to launch like a rocket, yet fly and be operated like an airplane. The team used lessons from aircraft and existing launch systems during development, with a goal of achieving "hands on turnaround" activities within a week, using a small crew size of approximately 50 people. Vehicle subsystems were arranged for one level deep access. Reliability, maintainability and supportability were factored into the flight and ground element designs. System level reliability requirements were developed and allocated down to the subsystem level. Infrastructure was co-located and processing and control facilities were minimized for efficient turnaround. 
The test vehicle flow, depicted in Figure 9 , shows the X-33 was to be processed at the launch pad horizontally, rotated to vertical, launched, flown to the test objective site, automatically safed, then transported back to the launch site. The original goal was to transport the vehicle using a modified Boeing 747 Shuttle Carrier Aircraft, but due to lack of access to one of the two aircraft, and alternate overland transport method was employed.

\section{B. X-33 Flight Test Profile}

The X-33 flight tests utilized a phased approach, employing a flight test envelop expansion with two landing sites (Figure 10).

The initial three suborbital flight tests to the first landing site were planned to demonstrate the structural loads, thermal, propulsion, aerodynamics and stability and control of the vehicle. The next three flight tests were planned to demonstrate one week or less turnaround of the vehicle. Flight Test 7 used relaxed aerothermal and stability constraints. Following performance upgrades to the vehicle, an additional set of up to eight test flights were planned to a longer range landing site, using longer burn times and achieving higher maximum suborbital speeds and altitude.

The initial landing site was Michael Army Airfield, located at Dugway, Utah. The first seven test flights planned to land at this sight within 14 minutes of launch. Powered flight duration was approximately three minutes. X-33 trajectories from the Edwards AFB launch site to Michael Army Airfield planned to reach maximum velocities of 6600 miles per hour (approximately Mach 11), peak altitude of 165,000 feet (approximately 31 miles), and a range of 450 miles.

The final eight test flights planned to land at Malmstrom Air Force Base in Montana. Powered flight duration was 3 minutes, 15 seconds, with total flight duration of 24 minutes. X-33 trajectories from the launch site to Malmstrom AFB were planned to reach maximum velocities of 7800 miles per hour (approximately Mach 13), peak altitude of 250,000 feet (47 miles), and a range of 950 miles.

\section{Flight Operations Center and Environmental Impact Statement}

This section describes the National Environmental Policy Act (NEPA) process the X-33 Program followed, which drove the requirement for an Environmental Impact Statement (EIS). Also, the X-33 flight operations center siting, layout and construction is summarized.

\section{A. X-33 Environmental Impact Statement}


The X-33 concept involved flight and ground element construction, test flights and operations. The National Environmental Policy Act of 1969 drove the requirement for an EIS, which evaluated the environmental consequences, mitigation and monitoring for all early candidate launch and landing sites. Environmental evaluation areas included flight safety, noise and sonic boom, airspace and air traffic, biological resources, threatened/endangered species and health and safety.

The EIS document was developed by a team of Lockheed Martin, NASA, FAA, DoD and DOI participants, and completed in an aggressive 14 month timeline. The Notice of intent was filed October 1996, the Draft EIS was released June 1997, Final EIS was released September 1997, and a favorable "Finding of No Significant Impact" Record of Decision was made November 1997.

\section{B. Flight Operations Center}

The X-33 Flight Operations Center (FOC), shown in Figure 11, consists of the infrastructure and systems required to horizontally process, rotate, launch and control the vehicle. The initial FOC site selected was at Edwards $\mathrm{AFB}$, due to its flight test heritage, capabilities, flight path clearances and proximity to the Lockheed Martin SkunkWorks X-33 assembly plant in Palmdale, CA. The final FOC site selection within the Edwards AFB perimeter was the result of an optimization of a number of criteria, including flight safety (expected casualty analysis), aerospike engine noise levels, ascent and entry sonic booms, explosive quantity-distance, transportation, utility and other construction costs, desert tortoise management zone designation, and Edwards AFB Precision Impact Range (PIRA) testing.

Design and construction for the FOC followed an aggressive timeline. The FOC PDR occurred December 1996, the CDR occurred October 1997, and approval of the EIS Record of Decision cleared the way for FOC groundbreaking November 1997. The facility was dedicated March 1999, and rotating launch mount T-0 umbilicals were installed June 1999 after construction and testing at NASA KSC.

The FOC is 25 acres in area, and includes a $35 \mathrm{ft}$. deep flame trench, $90 \mathrm{ft} . \mathrm{x} .105 \mathrm{ft}$. translating shelter, rotating launch mount (with T-0's and holddown posts) and strongback (for rotating the X-33 to and from vertical), LO2, $\mathrm{LH} 2, \mathrm{GO} 2, \mathrm{CH} 4, \mathrm{GHe}, \mathrm{LN} 2$ and GN2 commodity storage and transfer systems for vehicle propellants, engines, pressurants, purge and environmental control, 250,000 gallon water tower and transfer for sound suppression and firex, and LH2 flare stack. Other FOC hardware includes a vehicle positioning system with laser alignment, for mating the X-33 to the rotating launch mount, laser ordnance firing system and independent safing system. The site was constructed for only $\$ 32$ Million.

\section{Control Centers and Range}

This section summarizes the operations control center located adjacent to the FOC, the Range Control Center at Edwards AFB, Range Safety requirements, launch site and landing site Range support assets planned for X-33.

\section{A. Operations and Range Control Centers}

The X-33 Operations Control Center (OCC) was located near the FOC at Haystack Butte, and leveraged use of an existing control room. The center provided vehicle and ground systems monitoring and control capability for a small control team. Team console functions included the following: mission conductor, integrated systems manager, flight test, avionics, RCS/ECS and flight controls, propulsion, LO2, LH2 and operations control manager. Emergency response, public affairs and security also had interfaces with the OCC.

Range control was located at the Ridley Range Control Center at Edwards AFB. Functions included range safety, range control officer, weather, FAA and interface with downrange and landing area range assets. 


\section{B. Range Safety Requirements}

X-33 range safety requirements were tailored from the EWR 127-1 document by a team consisting of Lockheed Martin, ACTA, Inc., Air Force Flight Test Center, NASA, Utah Test and Tracking Range and USAF $30^{\text {th }}$ Space Wing personnel. Tailoring began December 1996, and the range safety requirements were approved by AFFTC and NASA February 1998, including flight analysis, airborne range safety system, flight control and range safety policies and processes. The preliminary flight data package was delivered February 1998, including overflight expected casualty analysis. The Edwards AFB commander approved the preliminary flight plan August 1999.

\section{Range Assets}

An extended test range alliance was formed, and a combination of government range tracking and control assets were used to assure safe X-33 command, control, monitoring, communications and range safety functions occurred during the critical prelaunch, launch, ascent, descent and landing phases.

Assets in the Edwards AFB launch site area, shown in Figure 11, include the NASA Dryden $23 \mathrm{ft}$. telemetry site for L-band and S-band downlink, the NASA Dryden $16 \mathrm{ft}$. radar and flight termination site, Leuhman Ridge site for 200 watt omni L-band uplink, OCC and Ridley RCC sites at Edwards, and Shadow Mountain S-band telemetry downlink site.

Landing site support for the Michael Army Airfield - Dugway UT included a mobile operations facility with telemetry and NASA-Dryden L-band and S-band uplink, and Wallops mobile radars and redundant flight termination systems. The extended test range alliance used a high altitude NASA

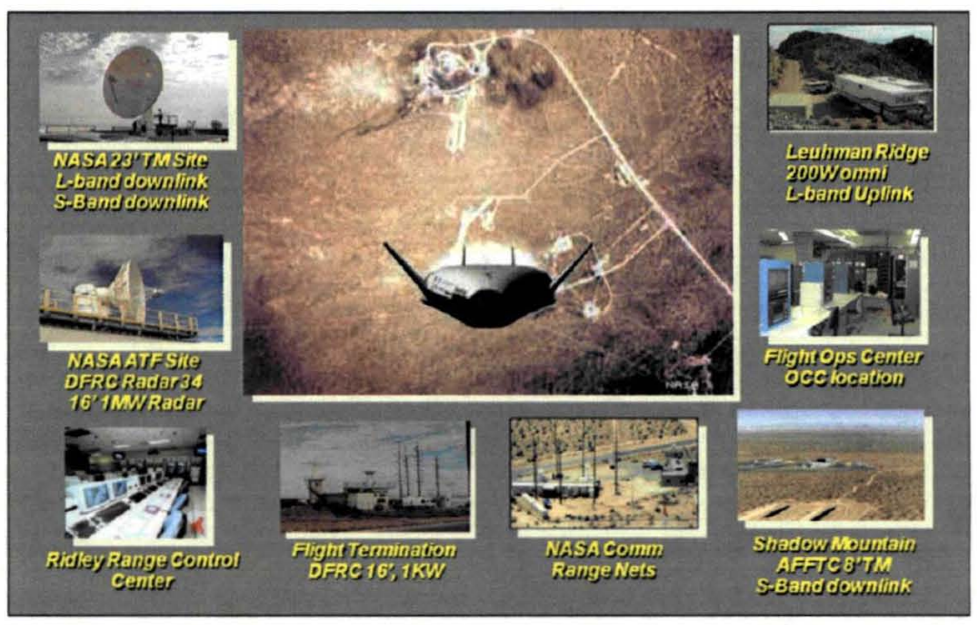

Figure 12. X-33 Range Assets - Launch Site

ER-2 aircraft to validate the test range connectivity from Edwards AFB to Dugway, UT September 1999.

Landing site range support assets for later test flights to Malmstrom AFB, MT were similar to the assets used for the Dugway, UT test flights.

\section{Single Stage to Orbit (VentureStar ${ }^{\mathrm{TM}}$ ) Development}

The full-scale SSTO development of VentureStar ${ }^{\mathrm{TM}}$ was pursued in parallel with X-33 Demonstrator development. SSTO vehicle designs were optimized continuously, based on X-33 subsystems, aerodynamics, ground systems, testing and operations planning lessons learned. Potential launch customer interface meetings were held throughout the development. The System Requirements Review was completed, March 1998. The System Architecture Review and Optimized Design Review were completed, July 1998. The JSC 28354 Human Rating Requirements evaluation was completed and reviewed with NASA, October 1998. A major NASA/LM ISS Visiting Vehicle Interface Meeting occurred February 1999, and the NASA ISS Crew Module Phase A Study findings were briefed in August 1999. A number of states displayed interest in, and participated in, planning meetings for potentially hosting the VentureStar ${ }^{\mathrm{TM}}$ launch and landing site.

\section{Lessons Learned}

This section summarizes lessons that were learned during the X-33 Demonstrator development, as well as some challenges. Lessons learned are expressed from the vantage point of the author who was part of the technical team throughout the development, and are categorized broadly as technical and programmatic.

\section{A. Technical Lessons Learned During X-33 Demonstrator Development}

Many technical lessons were learned during the X-33 development that impacted the demonstrator and the full scale follow-on SSTO vehicle design, and may have applicability to launch systems currently under development today. The SSTO vehicle was continuously optimized, often based on findings from X-33 structural, aerodynamic, 
propulsion, or concept of operations maturation. Findings and requirements derived from potential payload customer interface meetings also impacted the SSTO vehicle design.

X-33 lessons that drove improvements to the original SSTO concept include the following: utilize uniform TPS interface to the airframe, TPS standoff support structure optimized design for manufacturing and installation, extended use temperature for FRSI thermal insulation from $750 \mathrm{degF}$ (Shuttle) to $800 \mathrm{degF}$ (X-33 trajectory to Malmstrom AFB), and AFRSI thermal insulation blankets to 1500 degF., aerospike engine layout, engine load path integration with vehicle, mission module structure design, $10 \%$ propellant packing efficiency improvement, propellant tank design, increased use of graphite composite structure, aerosurface design, and utilization of a fleet of reusable mission modules for ground processing efficiency and launch availability.

The team learned how to quickly generate an EIS using a process that was fast and efficient, i.e., using NASA environmental management expertise, holding well-planned public scoping meetings in potentially affected towns, analyzing environmental impacts such as expected casualty analysis and sonic booms critical for inland flights. The team also learned how to quickly optimize, launch site selection, and obtain host launch site flight approval. Another lesson from X-33 is that developing Range Safety confidence in vehicle reliability is difficult without demonstrated flight history. Another lesson is to simplify abort planning and minimize modes, as it drives software, flight planning and IV\&V complexity.

One notable customer-derived lesson was that an escape system ${ }^{3}$ is required as part of the crew module, in order to meet JSC 28354 Human Rating Requirements, during pad-to-landing mission phases. Finally, an important X-33 lesson was that small expert teams with focused tasks and aggressive goals were highly productive.

\section{B. Programmatic Challenges and Lessons Learned During X-33 Demonstrator Development}

Programmatic Challenges - The X-33 Demonstrator faced many challenges during the 1996 - 2001 timeframe ${ }^{4}$. The X-33 was awarded during a time in which NASA was pursuing aggressive spacecraft developments, and supported a "faster, better, cheaper" high risk approach. Technical and economic expectations for the demonstrator were very high. The design required several new technologies, the concept of operations demanded quick turnaround, the development schedule was demanding, and the budget was highly constrained given the objectives. There was little margin for technical difficulties or failures.

There were a large number of stakeholders in the program, and some of them changed during this five year timeframe. The potential payload customer base was expansive, and included NASA, DOD, commercial satellite operators, NOAA and space tourists. Political stakeholders included NASA, White House, DoD, Congress and corporations - especially the X-33 team members. The cargo types and destinations were broad, and included LEO, MEO and GTO orbits, and sending humans and cargo to ISS. Every X-33 team company had management changes during the program. Lockheed and Martin Marietta merged into Lockheed Martin at the beginning of X-33, Rohr merged with BF Goodrich, Allied Signal merged with Honeywell, Rocketdyne-Rockwell became RocketdyneBoeing. This resulted in changes in personnel and, X-33 priority within the companies.

Funding became a challenge during the program, driven by technical issues with lightweight hydrogen tank development, and linear aerospike engine development. Task agreement rates with the US Government also changed during the period. NASA became more risk averse during this timeframe. Finally, the space launch market experienced a downturn in forecasted LEO satellites.

Programmatic Lessons - The programmatic lessons from X-33 are applicable to aerospace systems developments today. The X-33 objectives were aggressive, and therefore placed the demonstrator at high risk. In hindsight, the program was simply trying to accomplish too much with inadequate cost and schedule margin. The program was expected to perform the job of two vehicles, but was only funded for one. It was expected to function both as an X-vehicle (i.e., address technology risk) and a Y-vehicle (i.e., address cost risk). For a technology demonstrator, margin is required to cover the impact of failures of known high risk items, such as switching from a composite to metallic tank design. The program and stakeholders need to reach fundamental agreement on an acceptable level of technical and business risk, given their relative investment contributions. The program needs to be flexible and willing to balance competing requirements and possibly focus on a subset of stakeholders and their objectives. Program partners should be willing to shoulder comparable risks, or change the structure to primesubcontractors.

An objective "new product investment" economic analysis should be performed when commercial use is an elemental part of the business plan. Management structure should be flexible to change as the environment varies over time. Another lesson is that planners should only accept critical technologies - too many "must have" technology developments create unacceptably high risk to cost and schedule.

9

American Institute of Aeronautics and Astronautics 
From a programmatic perspective, the single stage concepts for lowering cost of space access are still valid and worthy of pursuit if the launch rate is sufficient, i.e., reuse high value hardware, reduce labor intensive tasks, increase reliability by minimizing staging, designing for engine out. Overall, the US Government's unconventional cooperative agreement procurement tool did allow flexibility for shared investment and risk, streamlined management, a small US Government program office, and government insight focus, versus oversight.

Finally, the history and lessons from this important NASA funded X-vehicle effort, as well as others such as X34 , should be better communicated to the public and industry, so that current and future space launch developers and stakeholders can benefit from the knowledge gained.

\section{Conclusion}

The X-33 Program achieved many milestones during development of the demonstrator. A significant level of aerospike engine testing was performed, $95 \%$ of the X-33 components were fabricated, tested and delivered, $75 \%$ of the vehicle assembly was completed by September 2000, most of the FOC was constructed in 12 months for only \$32million, an EIS Record of Decision was reached in only 14 months, the preliminary flight plan was approved, an extended test range alliance was formed and range assets were successfully tested. VentureStar ${ }^{\mathrm{TM}}$ SRR and SAR Reviews were completed by July 1998

NASA investment in the X-33 program totaled $\$ 912$ million, staying within its 1996 budget projection for the program. Lockheed Martin originally committed to invest $\$ 212$ million, and during the life of the program increased that amount to $\$ 357$ million. Although the effort did not result in an SSTO launch vehicle and service, lessons were learned that can be applied to aerospace systems developments today.

\section{References}

${ }^{1}$ Butrica, A.J., "X-33 History Project: Preliminary Project Description", URL: http://www.hq.nasa.gov/office/pao/History/x33/project.htm [cited 25 Feb. 2003].

${ }^{2}$ Kincaid, J. S., "Inside the Linear Aerospike", Launchspace Magazine, Vol 4, No. 4, 1 Sept. 1999, pp. 30-32, 50.

${ }^{3}$ Cirillo, W.M., "RLV Crew Module and Cargo Carrier Design Study", 26 August 1999.

${ }^{4}$ Hertzfeld, H.R., Williamson, R.A., Peter, N., "Launch Vehicles: An Economic Perspective", Space Policy Institute, George Washington University, September 2005.

${ }^{5}$ Meade, C.J., Lane, C.S. and Webb, R.L., "Achieving Responsive Access to Space- Market, Money, Mechanics and Management Lessons from X-33”, AIAA Responsive Space Conference, 2 April 2003. 


\section{X-33 Reusable Launch Vehicle Demonstrator, Spaceport and Range}

AIAA Space 2011 Conference

Long Beach, CA

September 27-29, 2011

Gary Letchworth gary.f.letchworth@nasa.gov (321) 867-1215
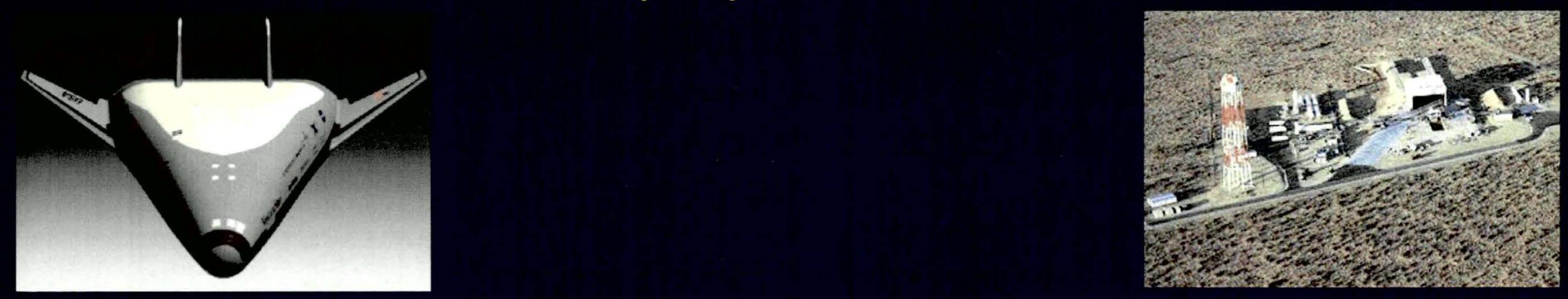


\section{Original X-33 Objectives}

- Reduce risk of building and operating an RLV fleet by building \& testing a $53 \%$ scale demonstrator

- Validate design tools and processes

- Validate lifting body characteristics, aerospike engine integration and aerothermal effects

- Demonstrate RLV technologies in a realistic flight environment

- Reusable cryogenic tankage

- Composite structures

- Durable TPS

- Advanced avionics and autonomous flight operation

- Reliable non-toxic propulsion

- Aircraft-like operations



Increase vehicle reliability, enable $10 x$ reduction in payload cost to LEO 


\section{X-33 Program Milestones}

- X-33 Phase 2 Cooperative Agreement (NASA and LM) award, July 1996

- Preliminary Design Reviews, Nov. - Dec. 1996

- Critical Design Review, Oct. 1997

- Flight Operations Center groundbreaking, Nov. 1997

- LO2 Tank arrives in Palmdale, Feb. 1998

- Linear aerospike engine related testing begins at Stennis, Oct. 1998

- Flight Operations Center dedication, Mar. 1999

- LH2 composite tank debond, Nov. 1999

- $95 \%$ of X-33 components fabricated, tested and delivered, vehicle assembly $75 \%$ complete, Sept. 2000

- Dual Engine Testing begins at Stennis, Dec. 2000

- X-33 Program Cooperative Agreement completed, Mar. 2001 


\section{X-33 Vehicle Configuration}



- Lifting Body

- Two J-2S Linear Aerospike Engines

- Metallic TPS Windward Side; AFRSI \& FRSI Leeward

Side

- Carbon-Carbon Nose Cap \& Leading Edges Length:

Width:

Fuel:

$69 \mathrm{ft}$

GLOW:

LH2:

LO2:

Take-off thrust:

Max. Speed:

$77 \mathrm{ft}$

LH2/LO2

285,000 lbs

30,000 lbs

$180,000 \mathrm{lbs}$

$410,000 \mathrm{lbs}$

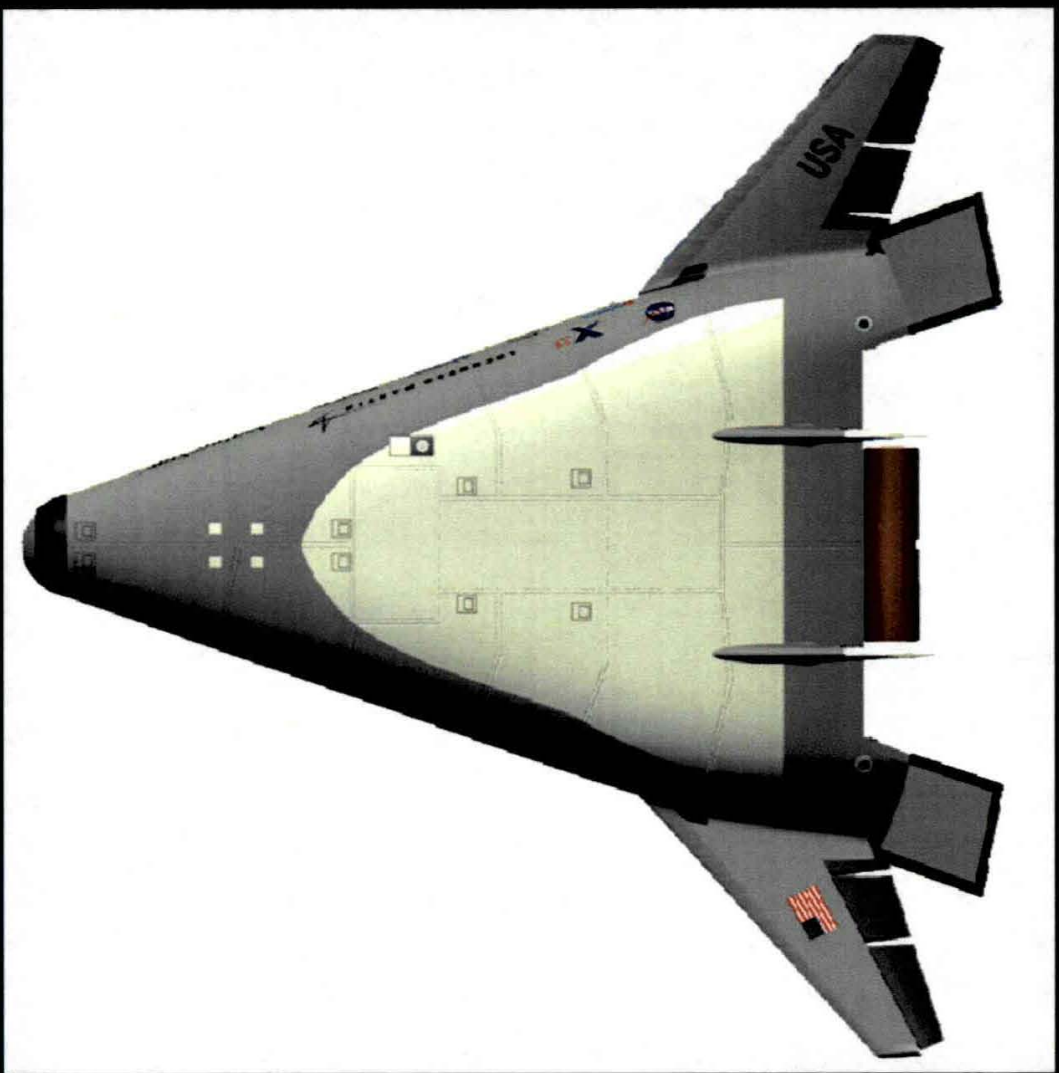

Mach 13.8






\section{X-33 Vehicle Isometric Cutaway}

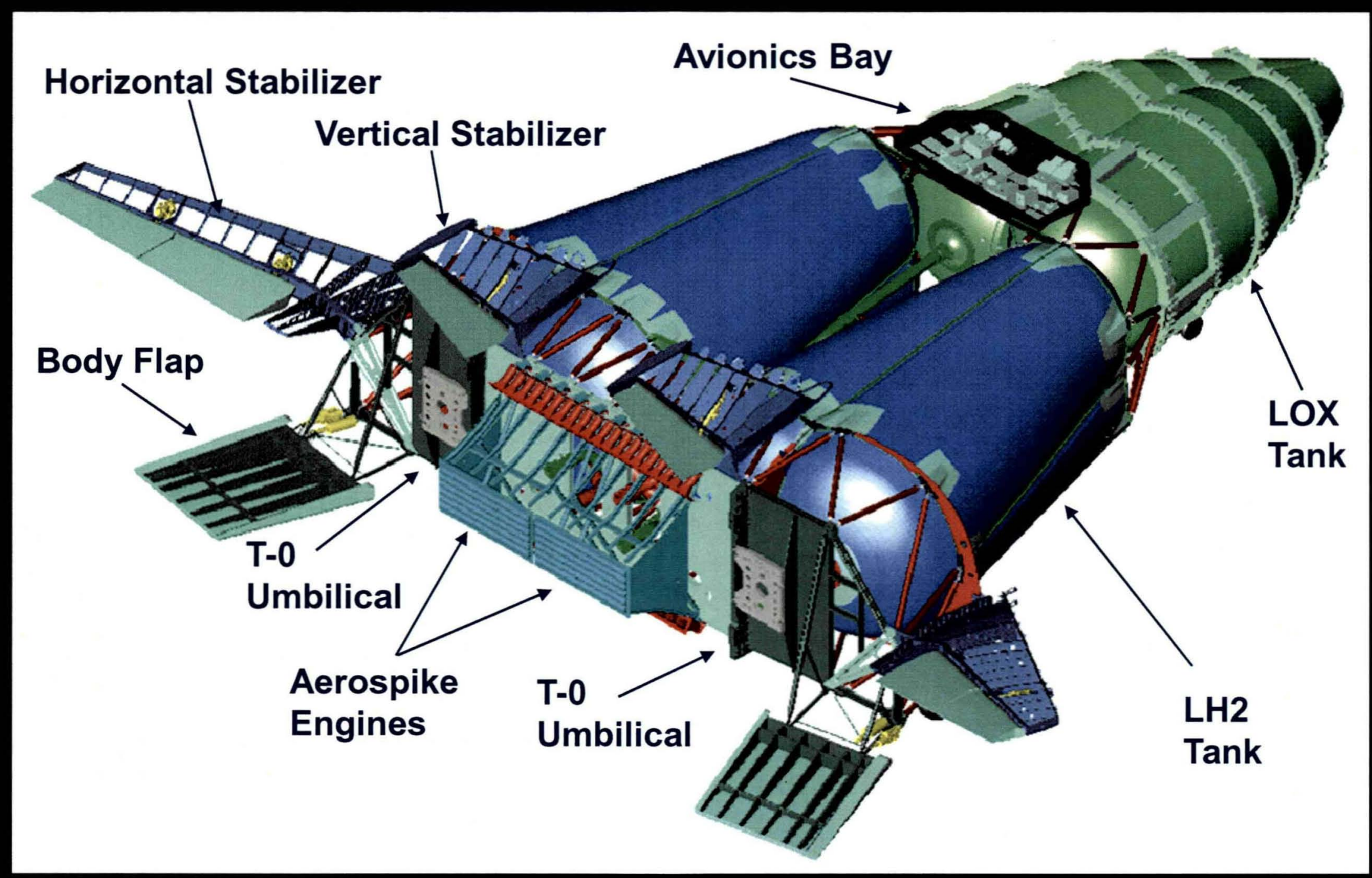




\section{Thermal Protection System}

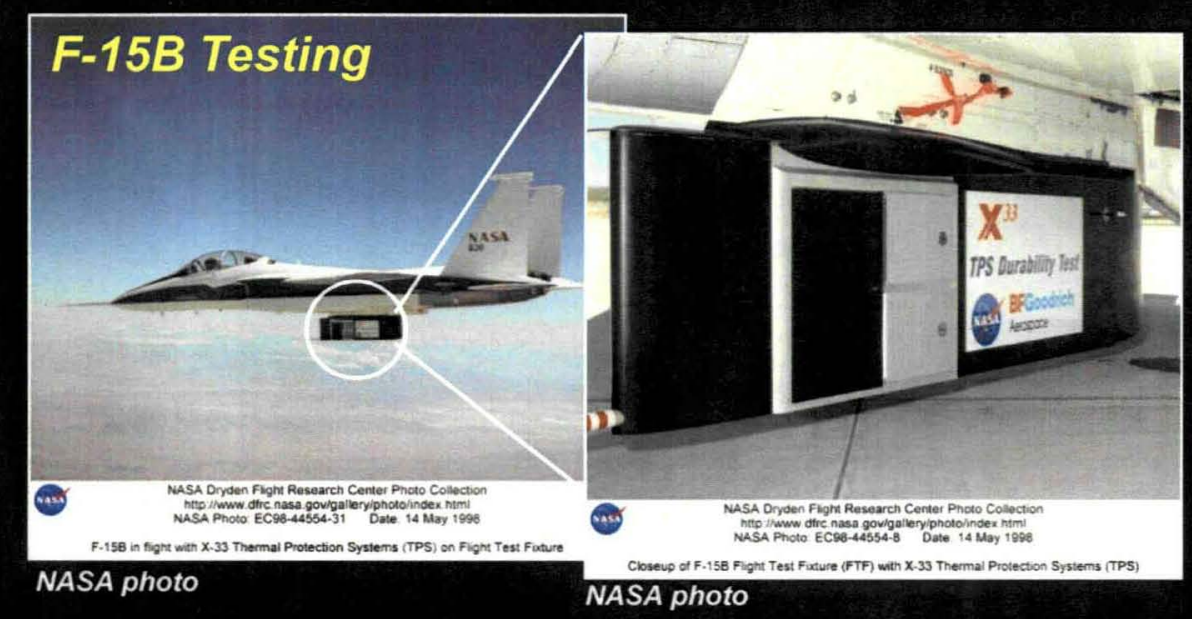

- Inconel TPS panels, seals, AFRSI flight-tested

- DFRC tests at Mach 1.4, $36,000 \mathrm{ft}$ using F-15B

- 6 flights May thru June 1998

- 9 panel TPS array test fit and demo R\&R, Sept 1998

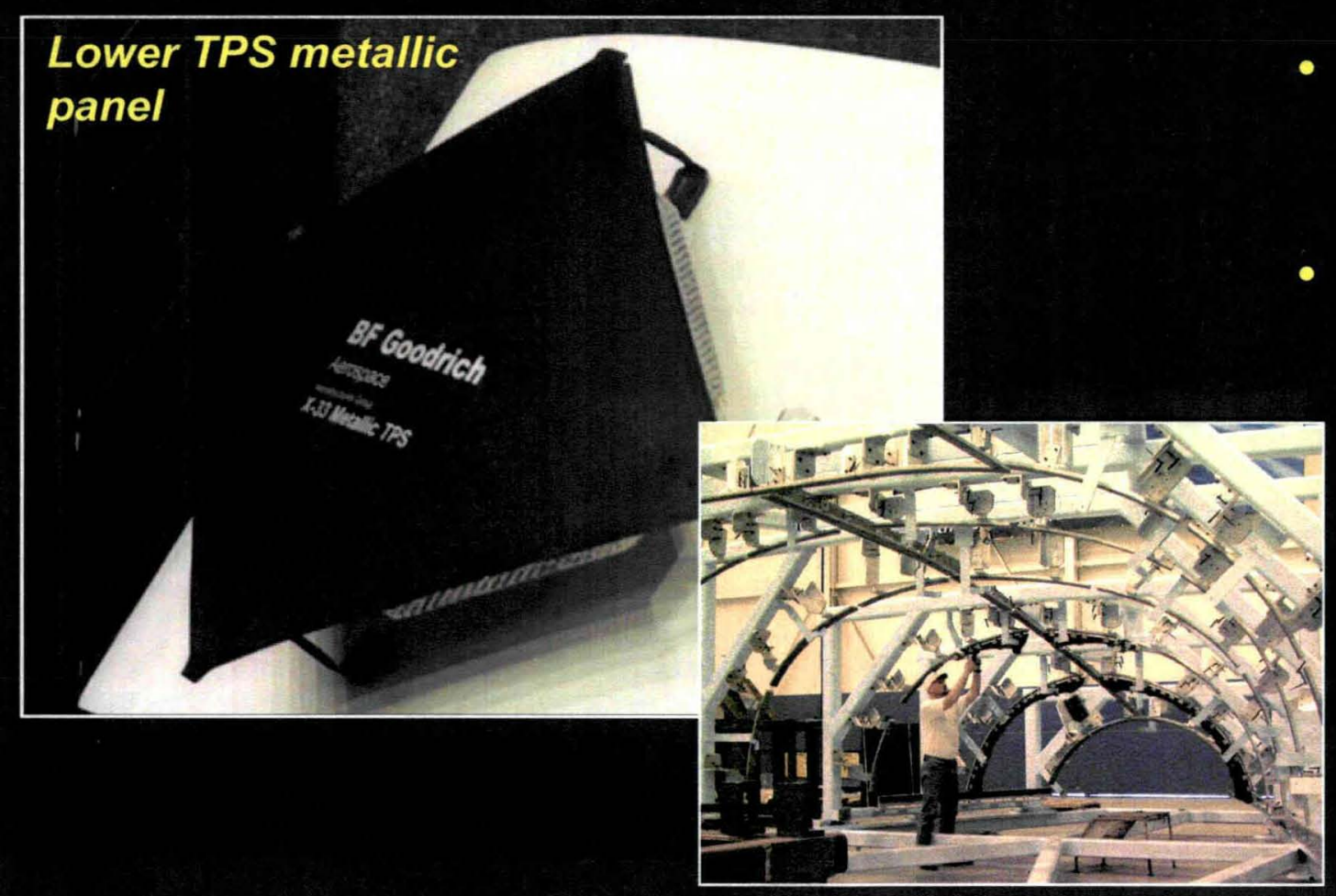

- $1^{\text {st }}$ upper TPS panels arrive Oct 1998

- $52 \%$ of 1241 panels delivered by Oct 1999

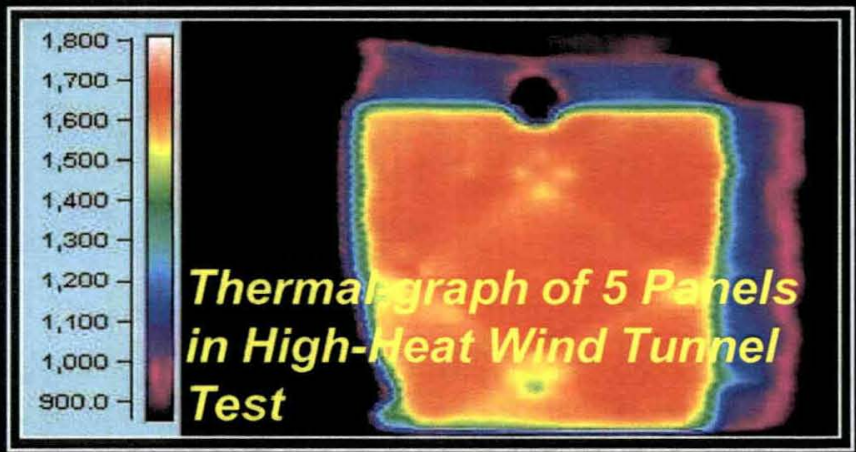




\section{X-33 Linear Aerospike Engine}

- Two X-33 linear aerospike engines

- 10 combustor nozzles (thrust cell) arrayed along two ramps

- Altitude compensating avoids under or over-expansion
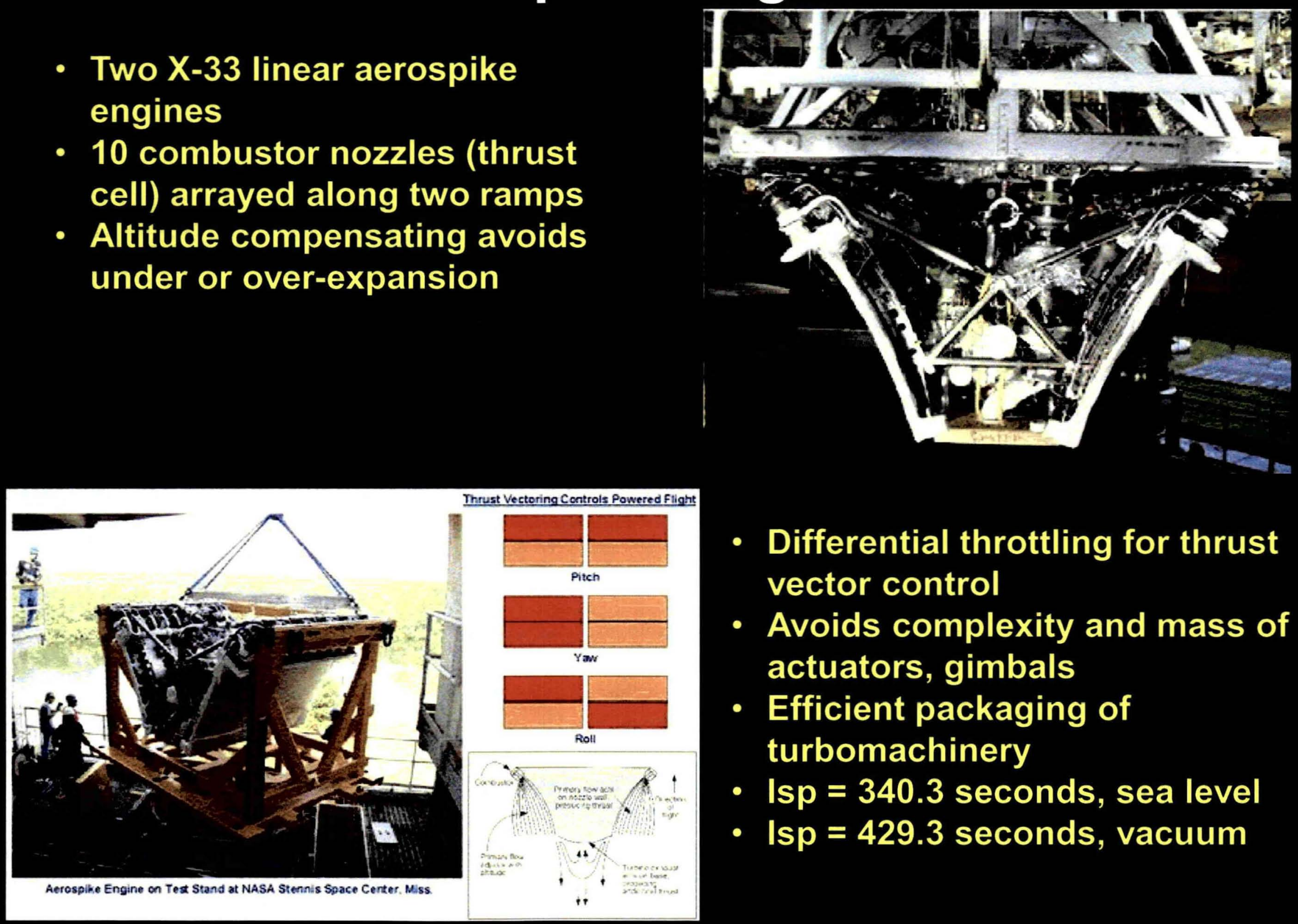

- Differential throttling for thrust vector control

- Avoids complexity and mass of actuators, gimbals

- Efficient packaging of turbomachinery

- Isp $=340.3$ seconds, sea level

- Isp $=429.3$ seconds, vacuum 


\section{X-33 Linear Aerospike Testing}

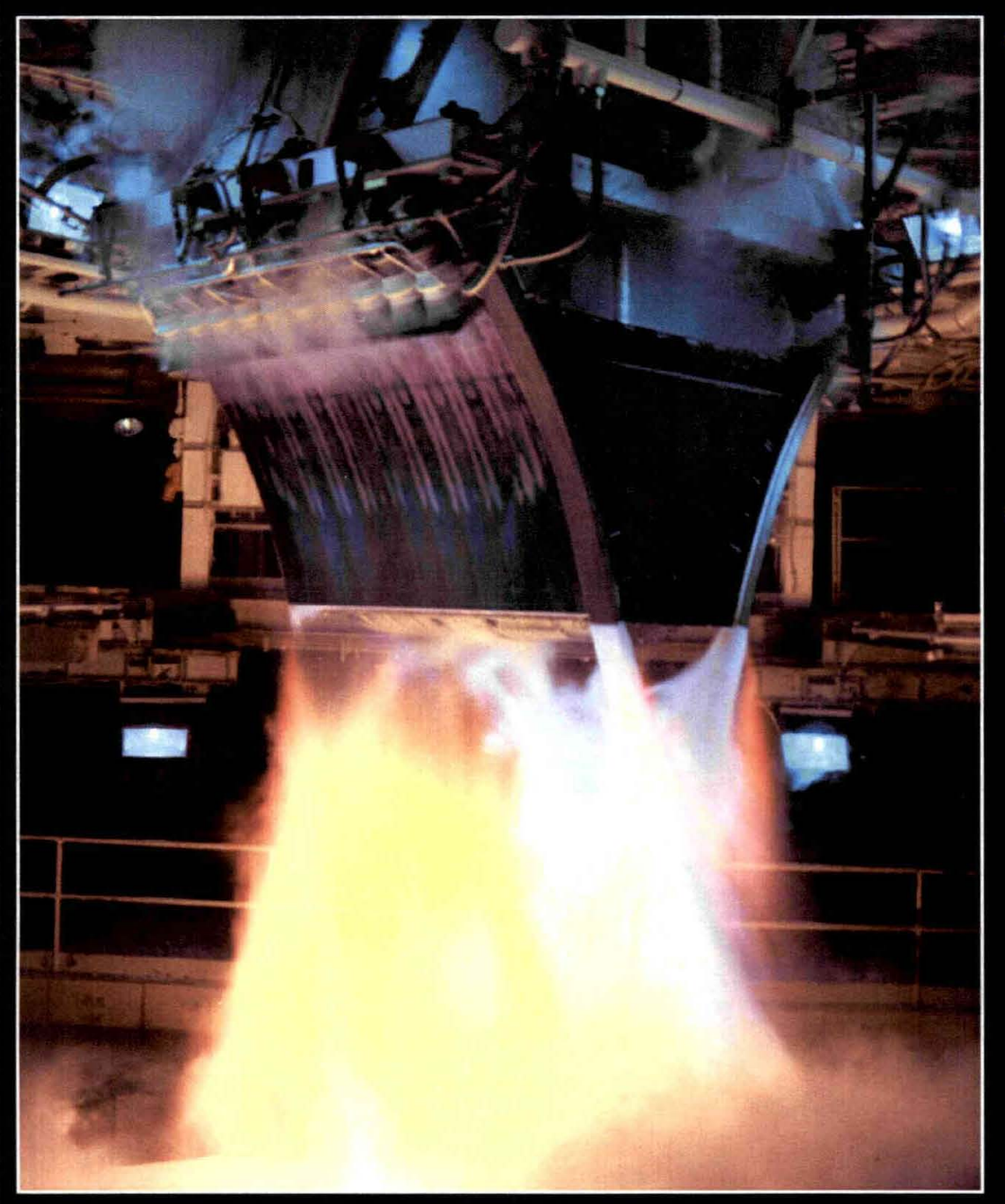

- Successful extensive test program

- Single thruster - 13 tests, 985 seconds

- Multi-Cell - 10 tests, 49 seconds

- Powerpack - 17 tests, 1506 seconds

- First engine delivery to Stennis July 1999

- Single Engine - 14 tests, 1513 seconds

- Full power achieved in 6 tests

- Tandem Engine Testing Initiated Dec 2000

- Successful Cold Flow and Ignition Tests

- Successful 20 and 90 second Tests

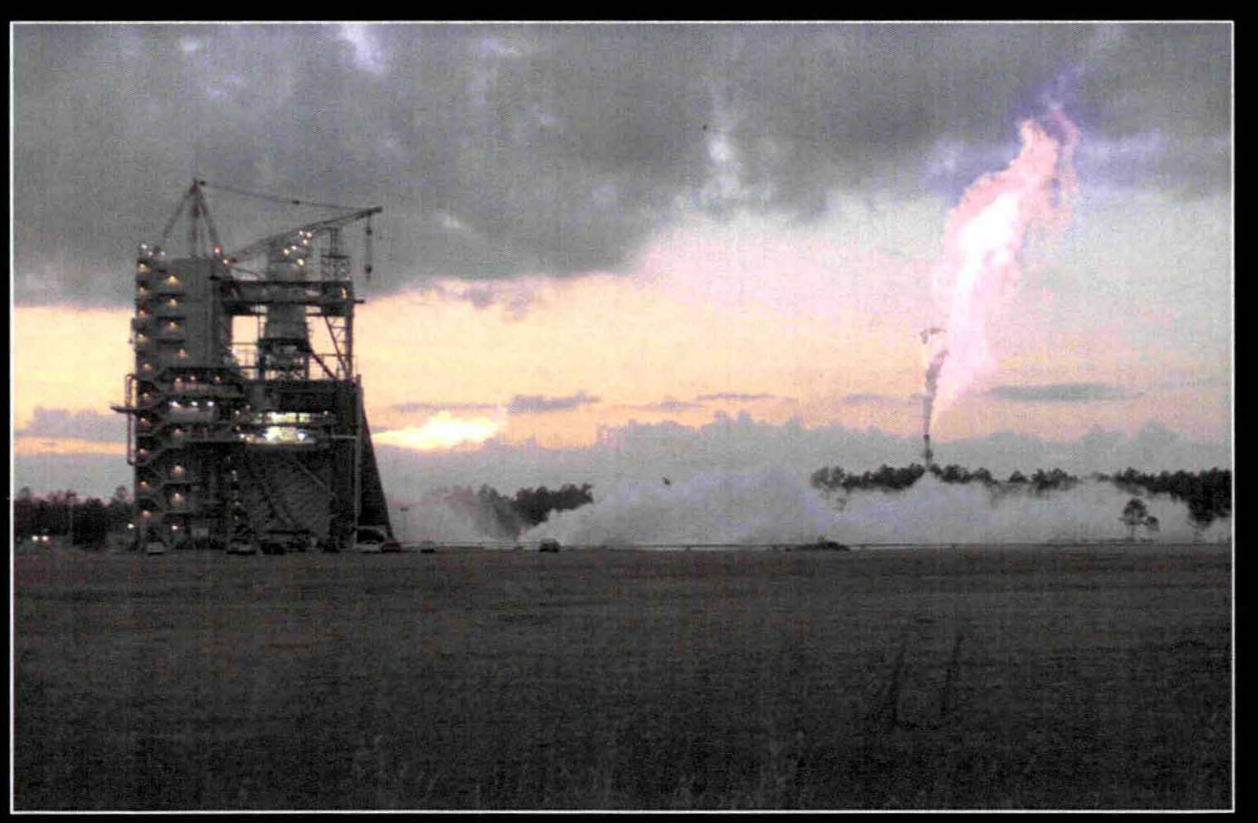




\section{X-33 LOX Tank}

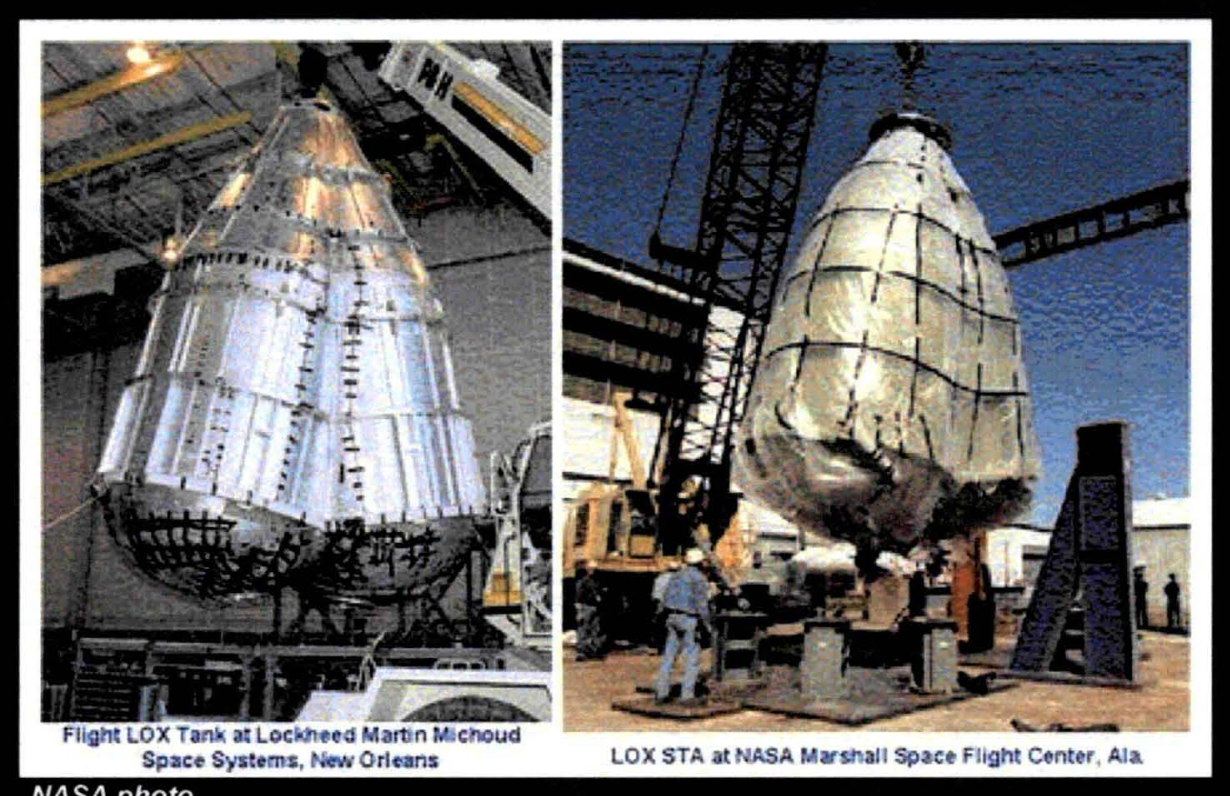

- Two tanks designed and built by LM Michoud Space Systems

- Al-Li material

- Structural Test Article (STA) successful test at MSFC, May 1999

- Flight Article arrived Palmdale Feb. 1998 NASA photo
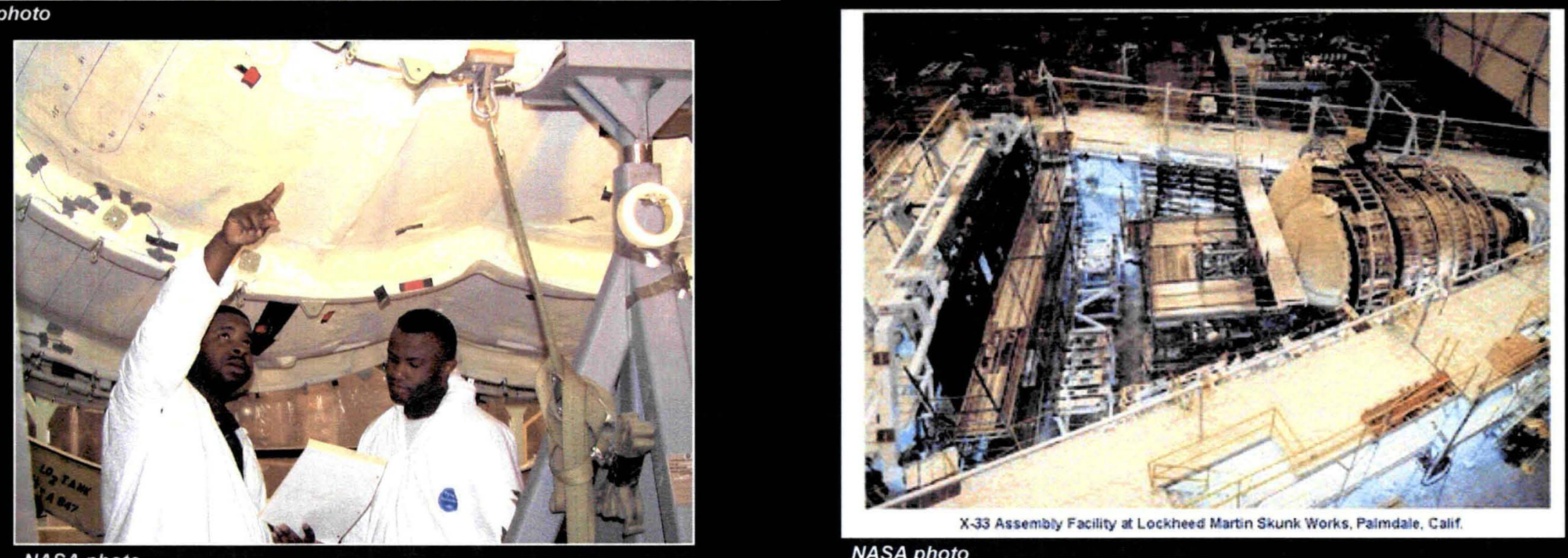

X 33 Assembiy Facility at Lockheed Martin Skunk Works, Paimdale, Calif 


\section{X-33 Composites: LH2 Tank and Structures}

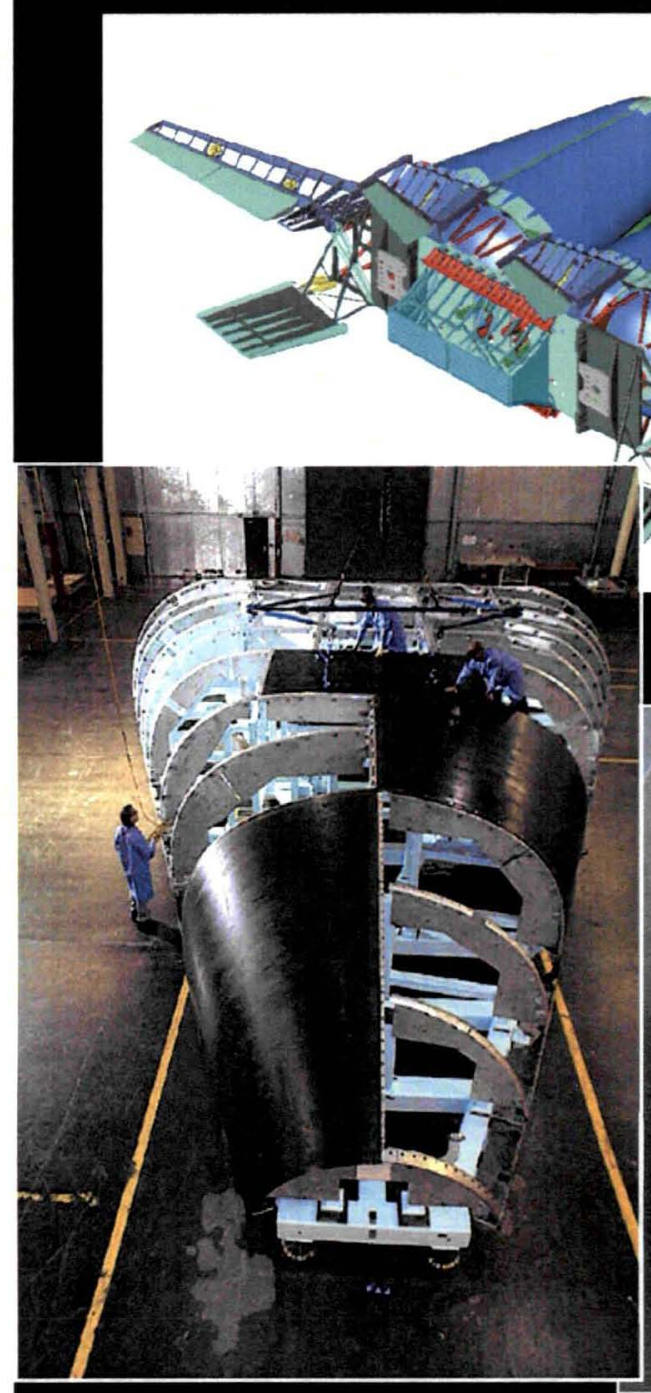

Upper TPS Composite

Panel Structure
- LH2 Tanks

- Two multi-lobe tanks located in aft

- Upper TPS structure

- Intertank structure

- Aft thrust structure

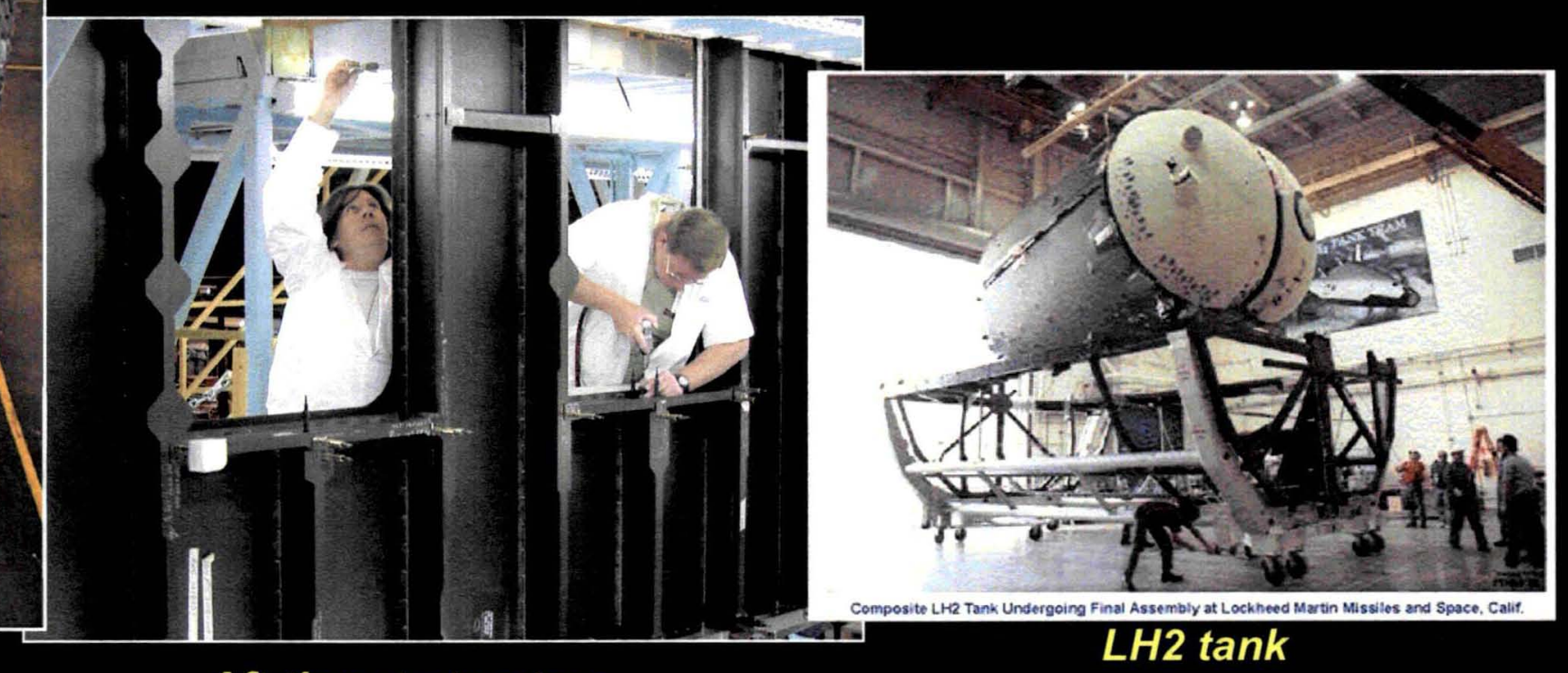

Aft thrust structure 


\section{X-33 LH2 Tank Testing}

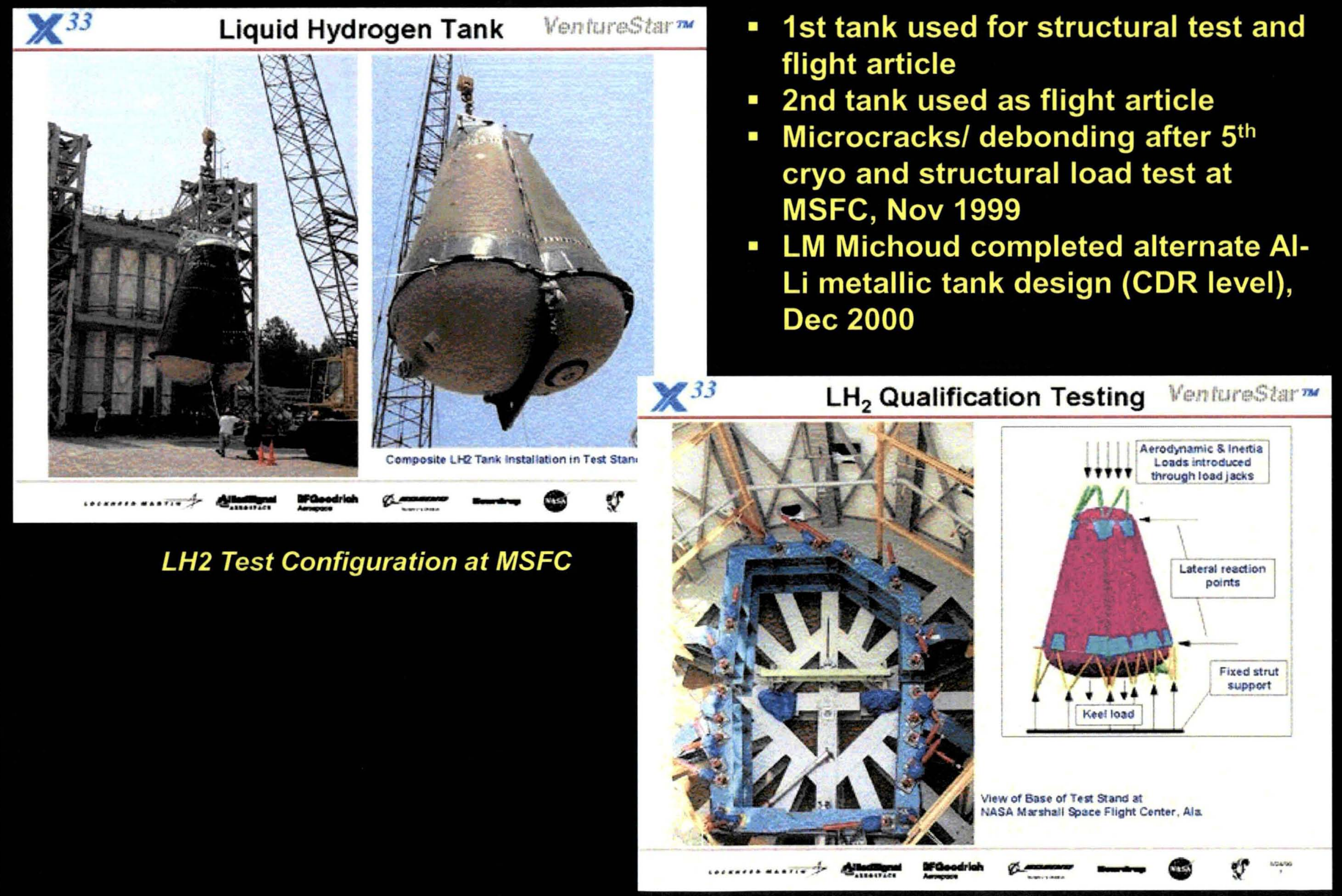




\section{Other X-33 Vehicle Subsystems}



- Reaction Control System (Gencorp)

- 8 thrusters verification-tested

- GO2/CH4 tanks installed by Dec. 1998

- Avionics

- LM-Sanders delivered first two VHM health nodes Nov. 1998

- One-level deep component accessibility

- Initial vehicle power-on testing Dec. 1999

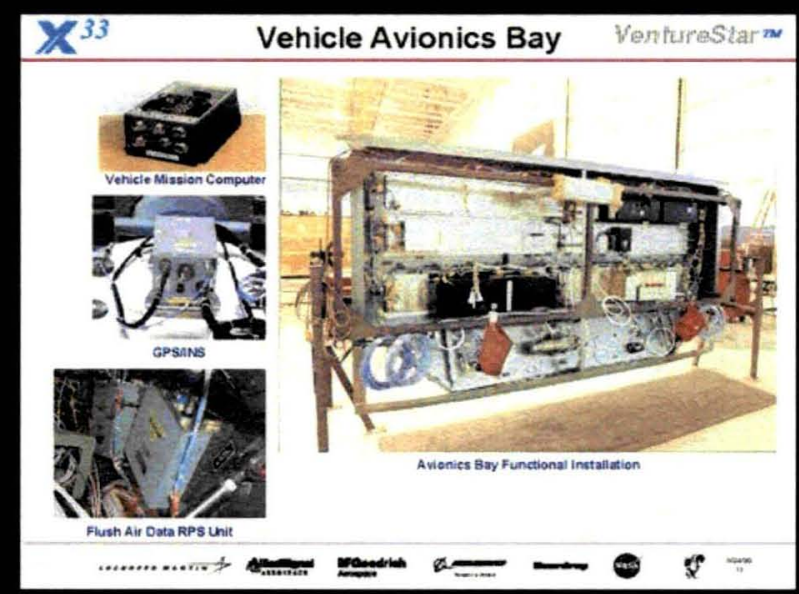

Source: NASA

- Aerosurfaces

- Vertical stabilizers, body flaps, canted fins

- Landing Gear
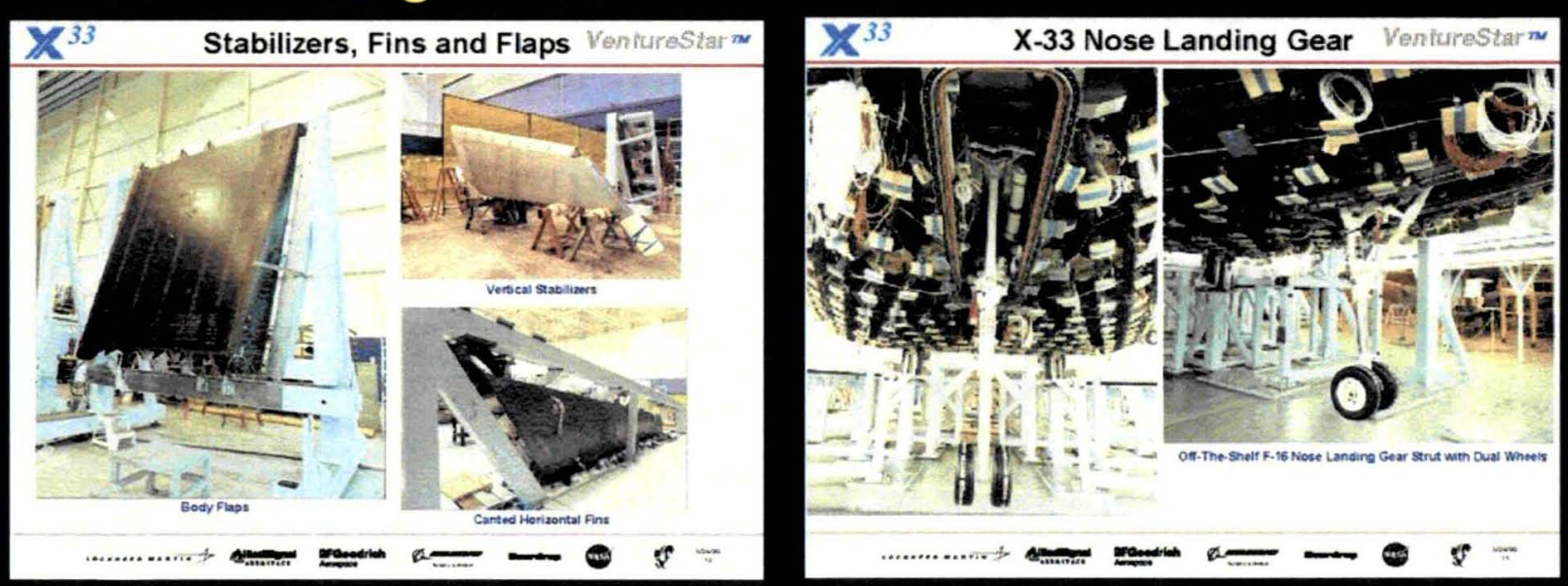


\section{X-33 Operations Concept}

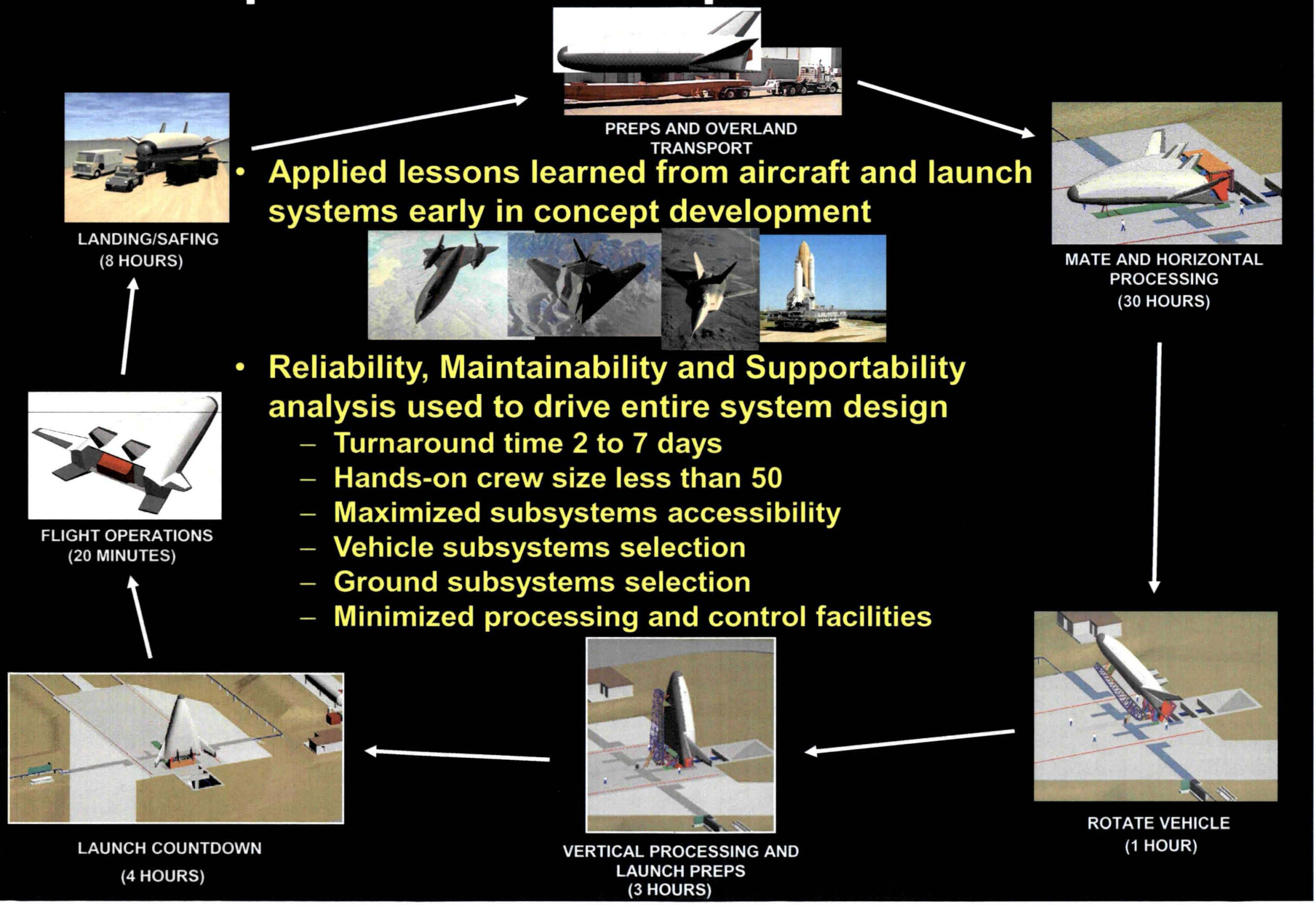




\section{X-33 Flight Test Profile}

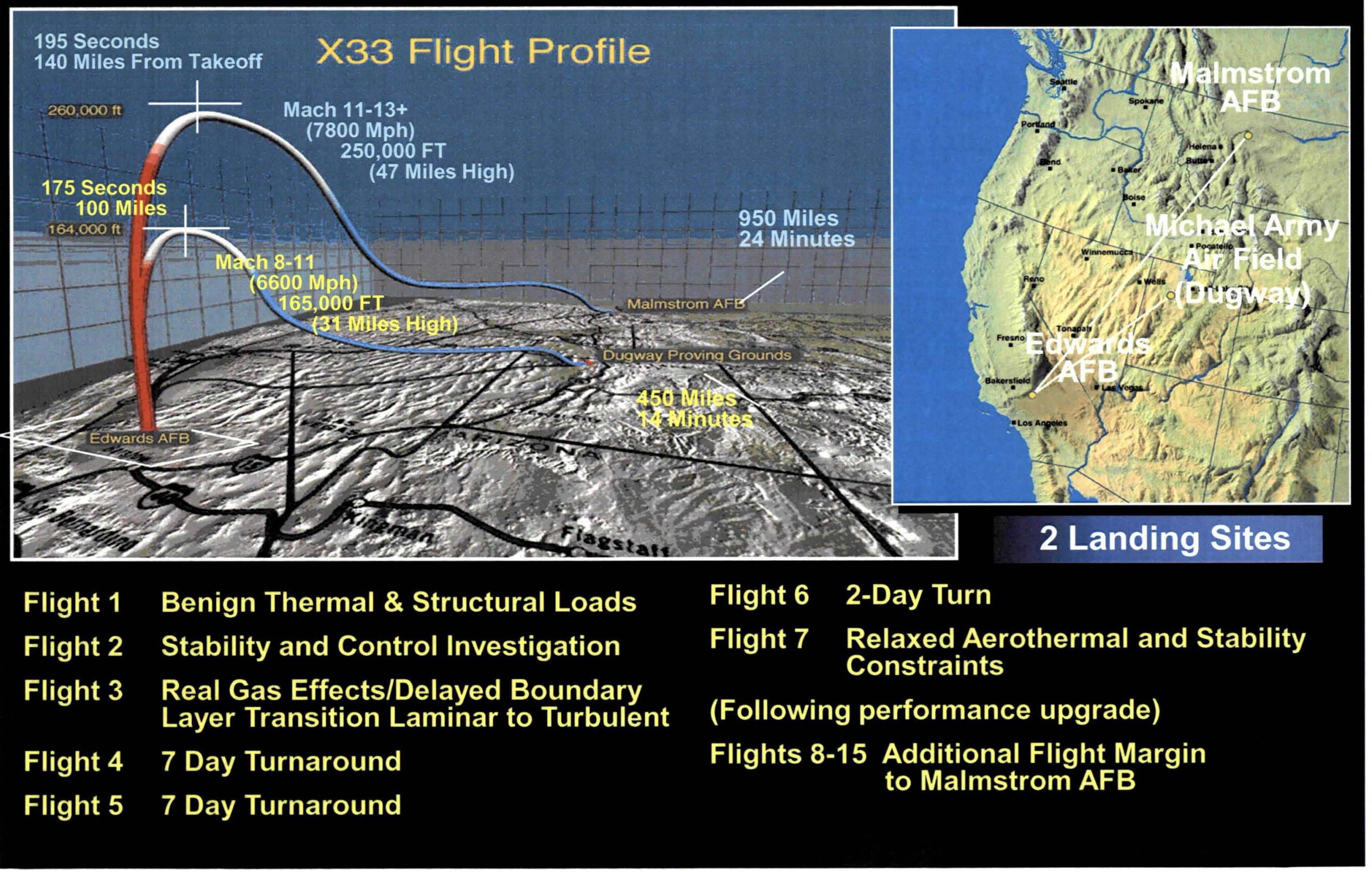




\section{Environmental Impact Statement}
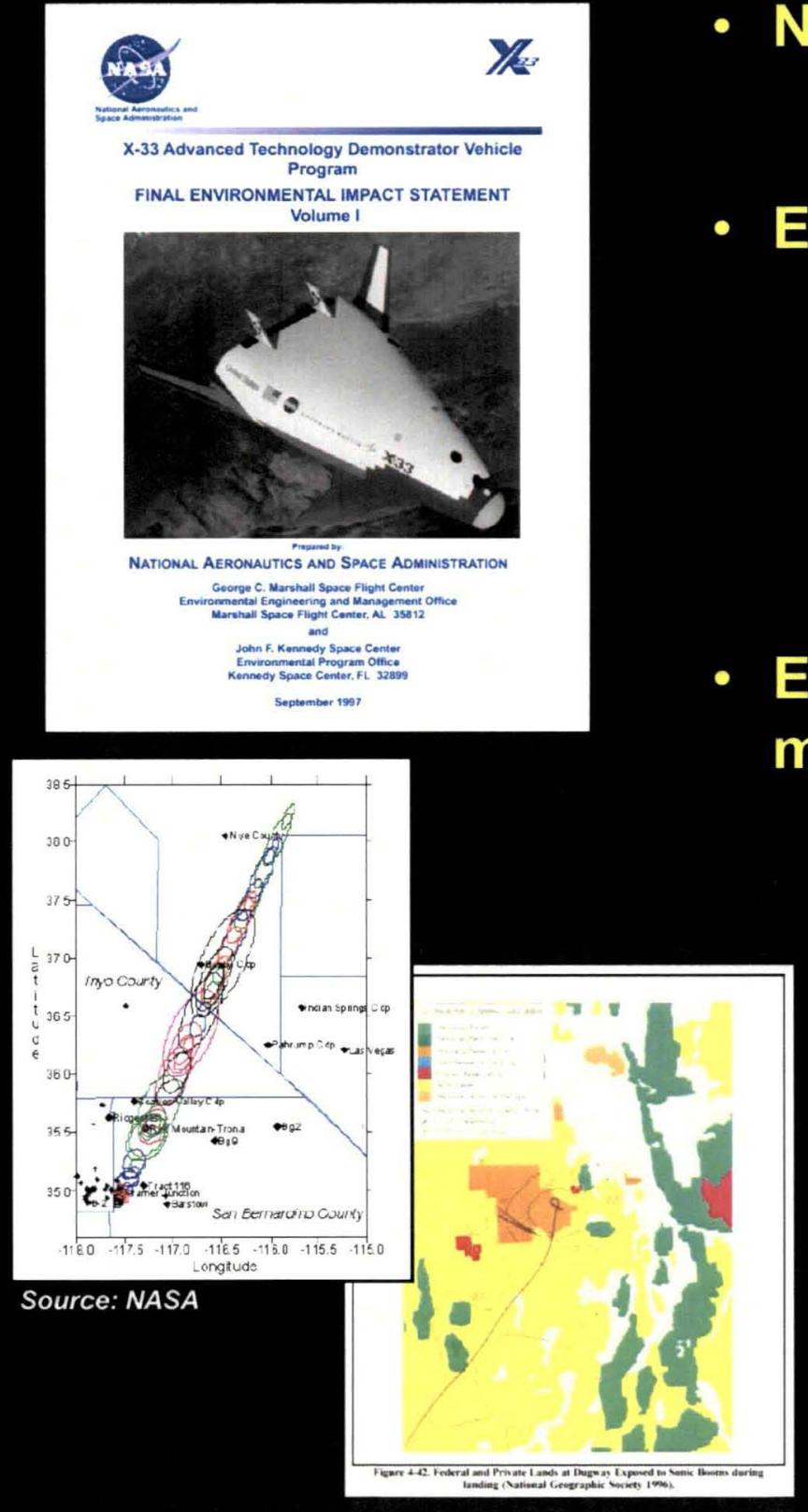

- National Environmental Policy Act of 1969 (NEPA)

- Environmental Impact Statement (EIS) required

- EIS process successfully completed in 14 months

- NASA-MSFC, NASA-KSC, FAA, DoD, DOI-BLM, LM

- Notice of Intent, Oct. 1996

- Draft EIS, June 1997

- Final EIS, Sept 1997

- Record of Decision, Nov. 1997

- Environmental consequences, mitigation and monitoring for candidate launch/ landing sites

- Flight safety

- Health and safety

- Noise and sonic boom

- Airspace and air traffic

- Biological resources

- Threatened \& endangered species

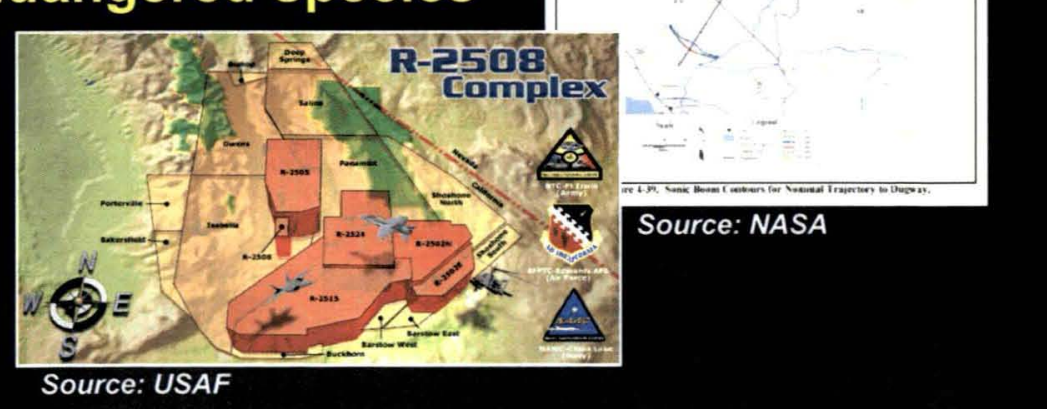




\section{X-33 Flight Operations Center - Siting}

- Edwards AFB area

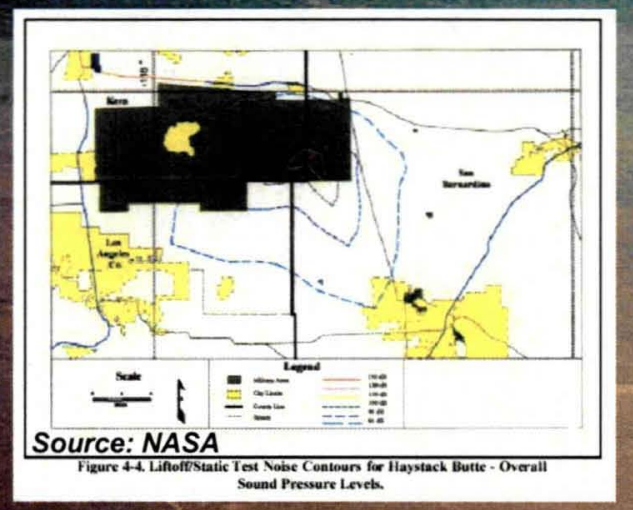

\section{Liftoff Noise}

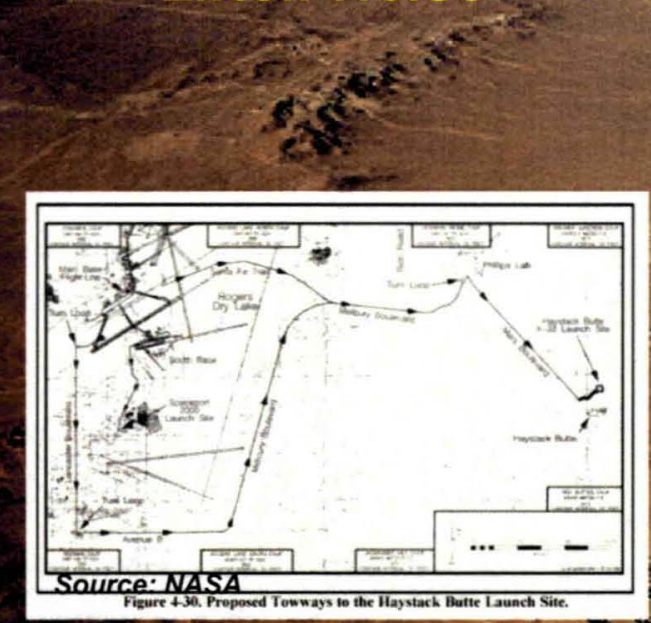

Transportation
- R2508 restricted airspace $(200 \times 110 \mathrm{mi}$.)

- Proximity to Skunk Works/ X-33 final assembly

- Siting factors withintedwards AFB

- Flight saiety (expected casualty)

- Test firing and liftofi noise

- Sonic boom

- Transportation, utilities-and other construction costs

- Desert tortoise Management Zone

- Explosive quantity-distance (QD)

cos - Precision Impact Range testing

\section{- Haystas B serstected}

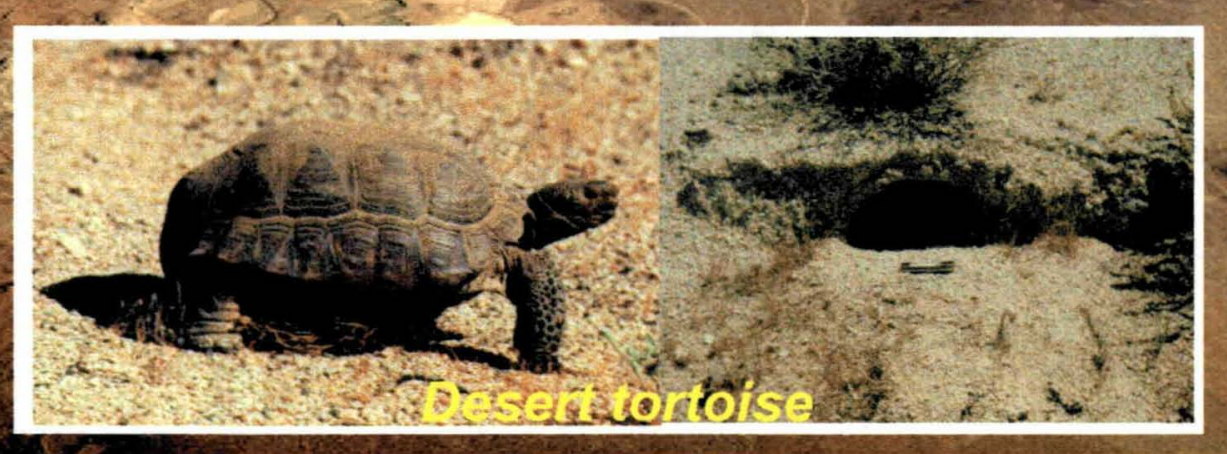

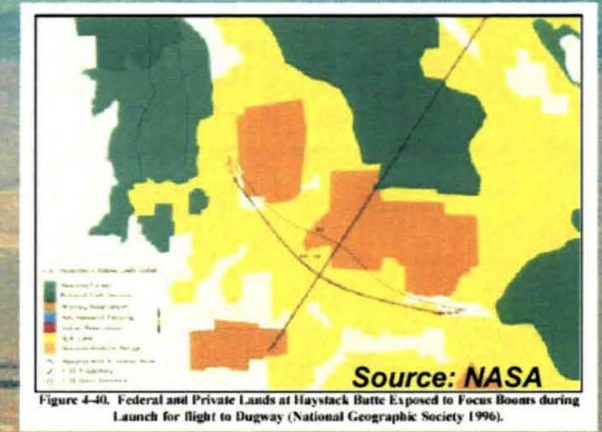

Sonic boom

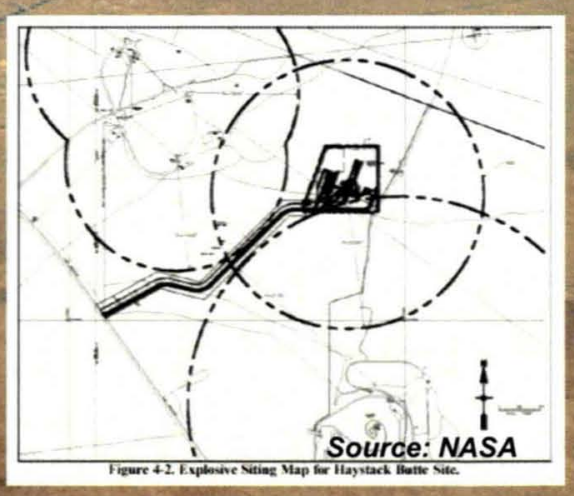

Explosive QD. 


\section{Flight Operations Center - Construction}

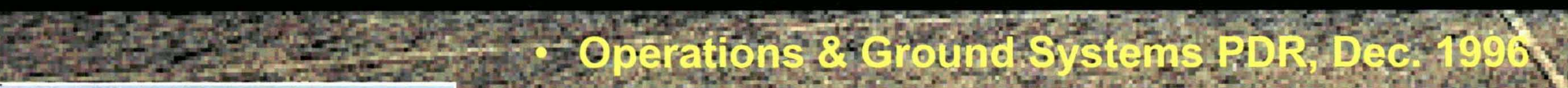

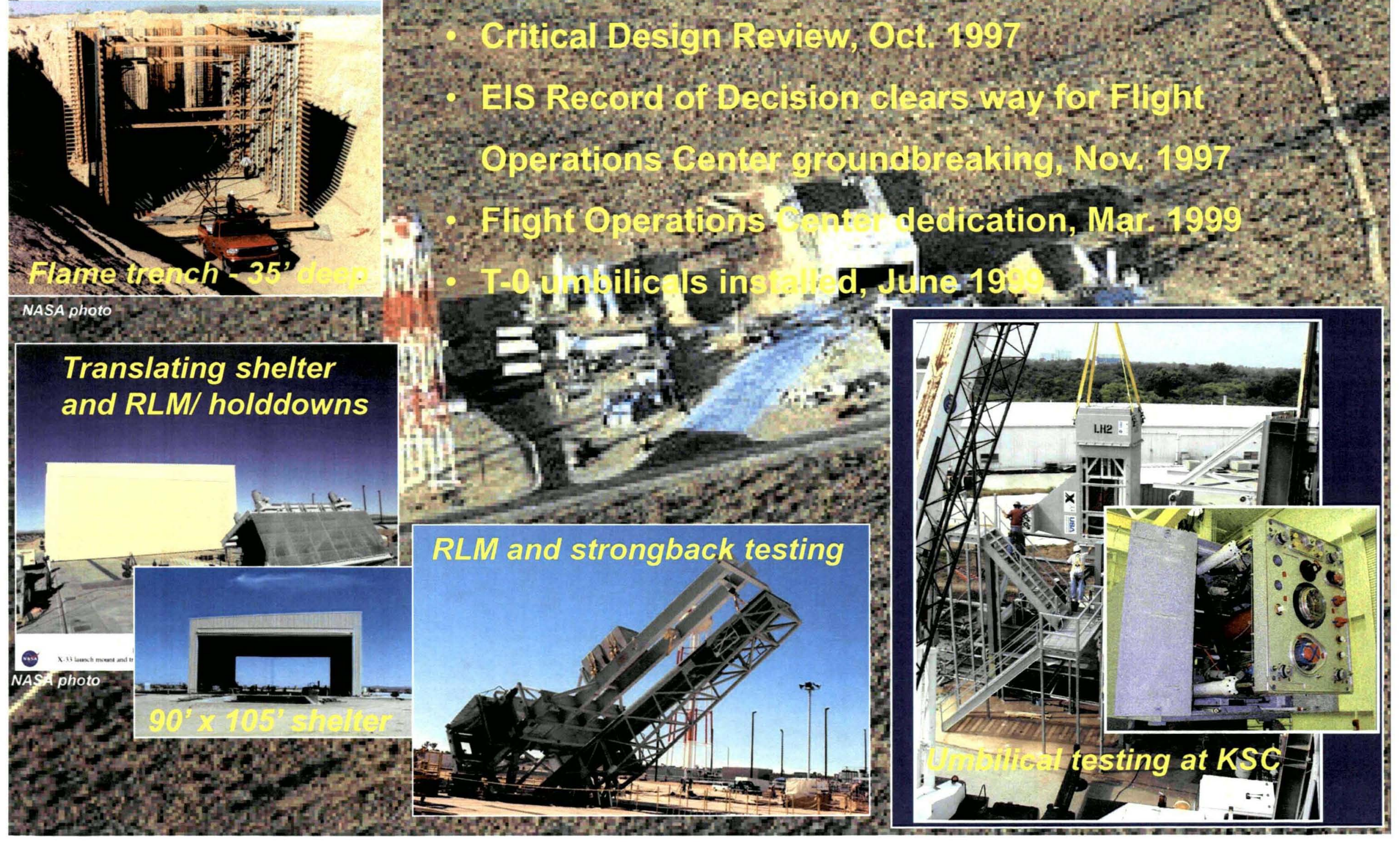




\section{Flight Operations Center}

\section{- 25 Acre, \$32 Million Center On Edwards Air Force Base}

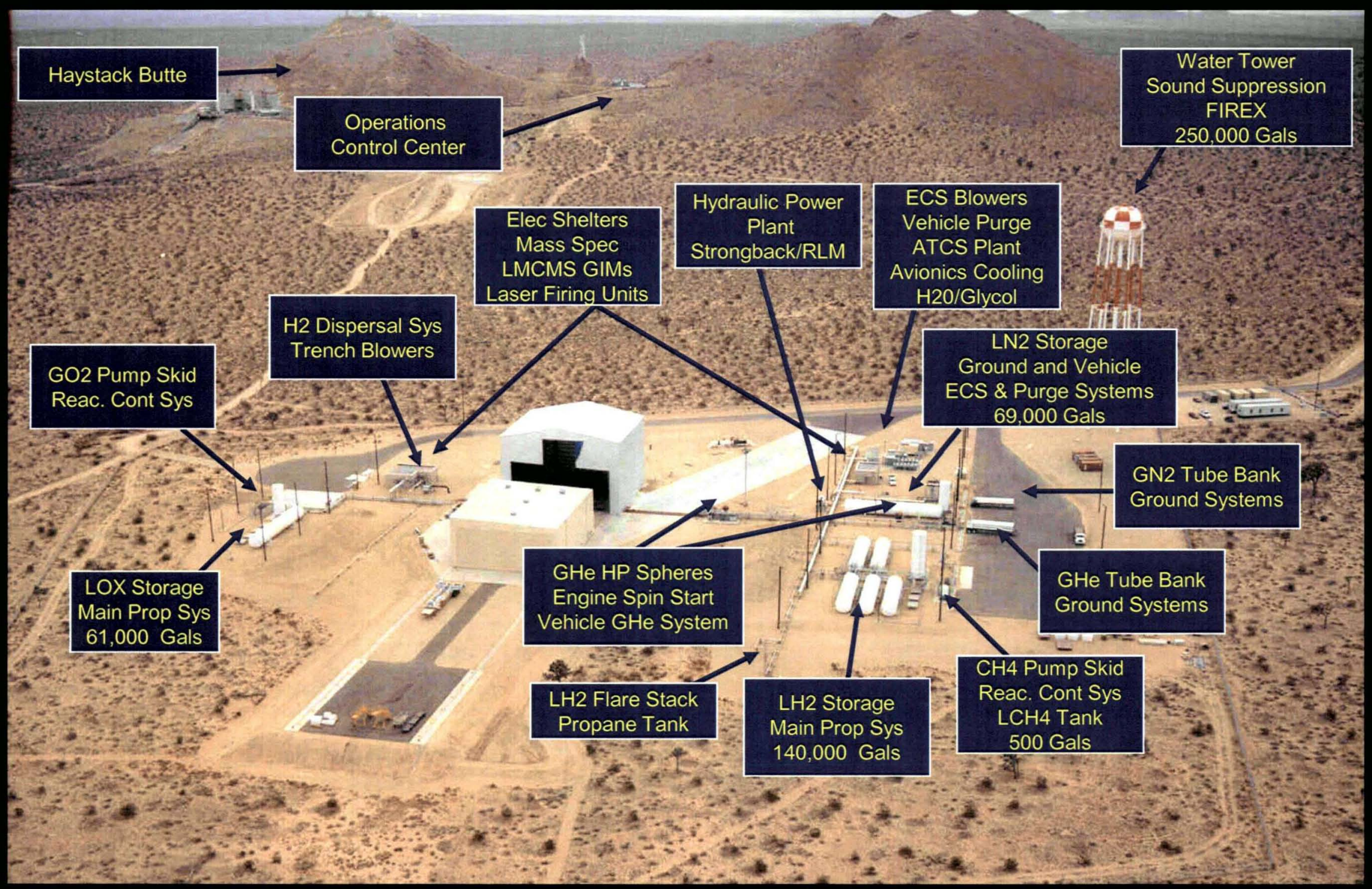




\section{Operations Control Center}

- OCC located at Haystack Butte

- Mission Conductor

- Integrated Systems Manager

- Flight Test

- Avionics

- RCS/ Flight Controls/ ECS

- Propulsion

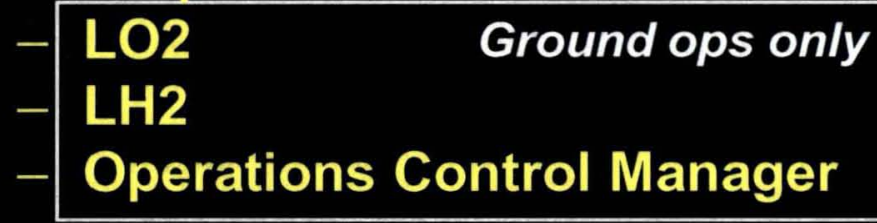

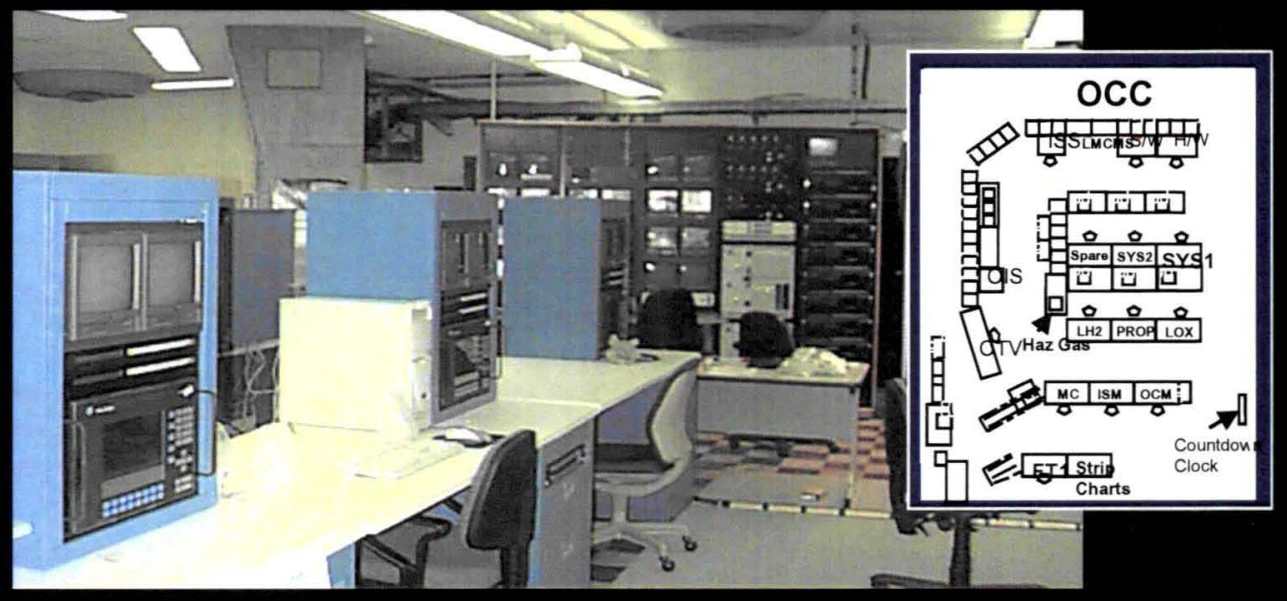

Operations Control Center

- Primary Range Control located at Edwards AFB

- Range Safety

- Range Control Officer

- Weather

- FAA

- Assets also located downrange

- Other OCC interfaces

- Emergency response

- Public affairs

- Security

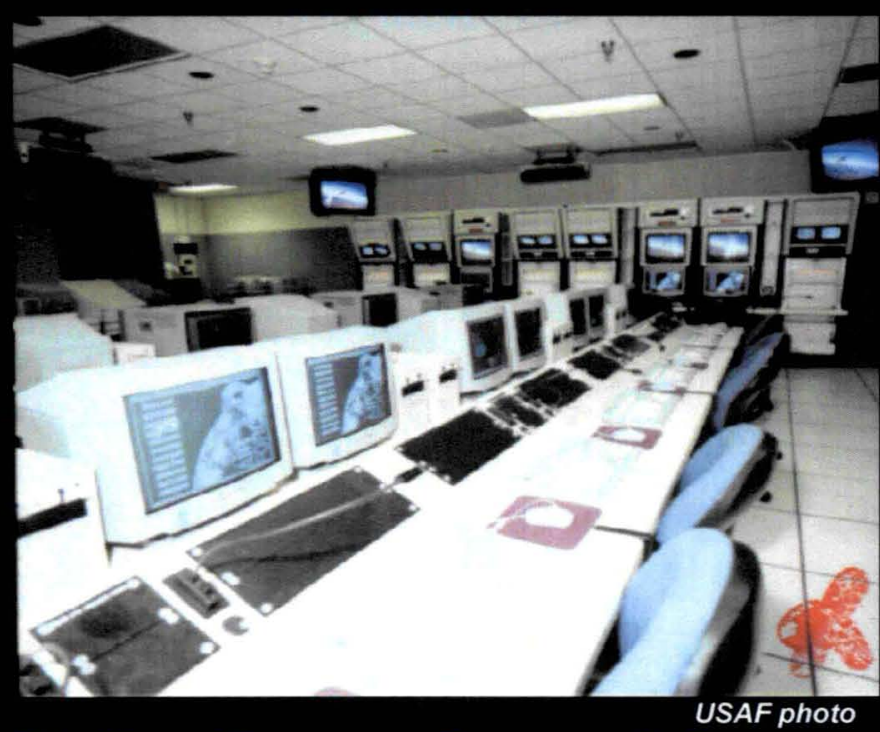

Ridley Range Control Center 


\section{Range Safety Requirements}

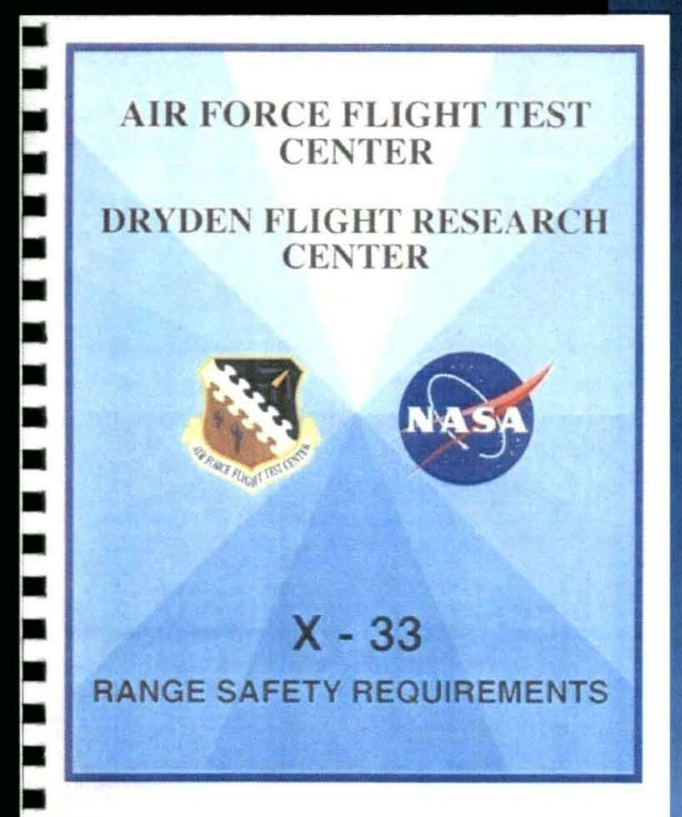

Source: AFFTC, DFRC

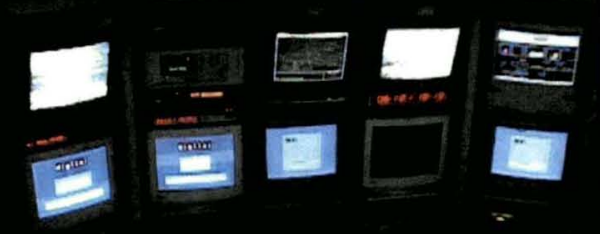

RSO console at Ridley USAF photo

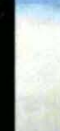

- X-33 Range Safety Requ' tents Tailored from EWR 127-1

- LM, ACTA, AFFTC, DFRC, UTTR, $30^{\text {th }}$ SW

- Initiated Dec. 1996

- $1^{\text {st }}$ Draft, Mar. 1997

- Approved by AFFFC and DFRC, Feb. 1998

- X-33 Range Safety Requirements Document contents

- Range Safety Policies and Processes

- Flight Analysis Requirements

- Airborne Range Safety System Requirements

- Flight Control Requirements

- Preliminary Flight Data Package delivered Feb. 1998

- Preliminary Flight Plan Approval from Edwards AFB Commander,

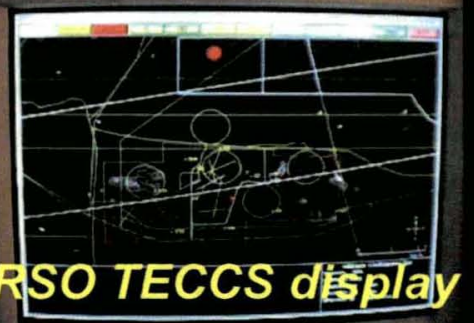




\section{Range - Launch Site Support}

\section{Edwards AFB, CA}

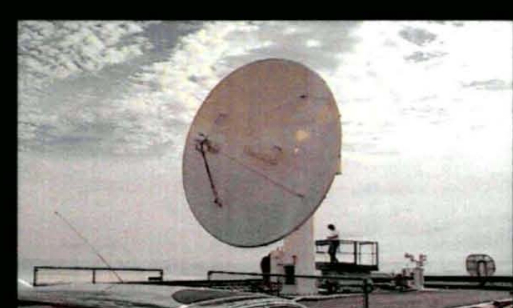

NASA 23' TM Site L-band downlink S-Band downlink

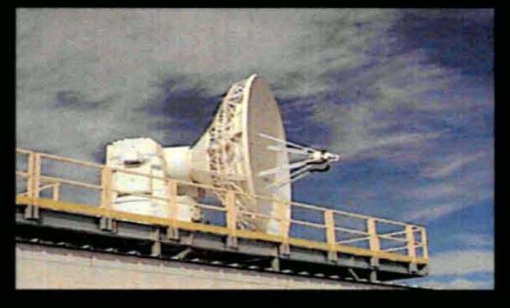

NASA ATF Site DFRC Radar 34 16' 1MW Radar

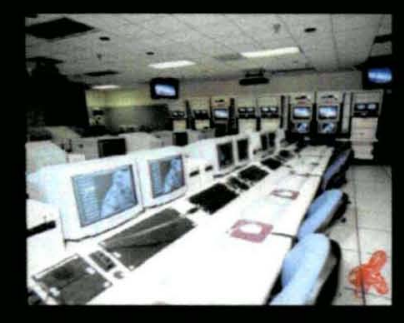

Ridley Range Control Center

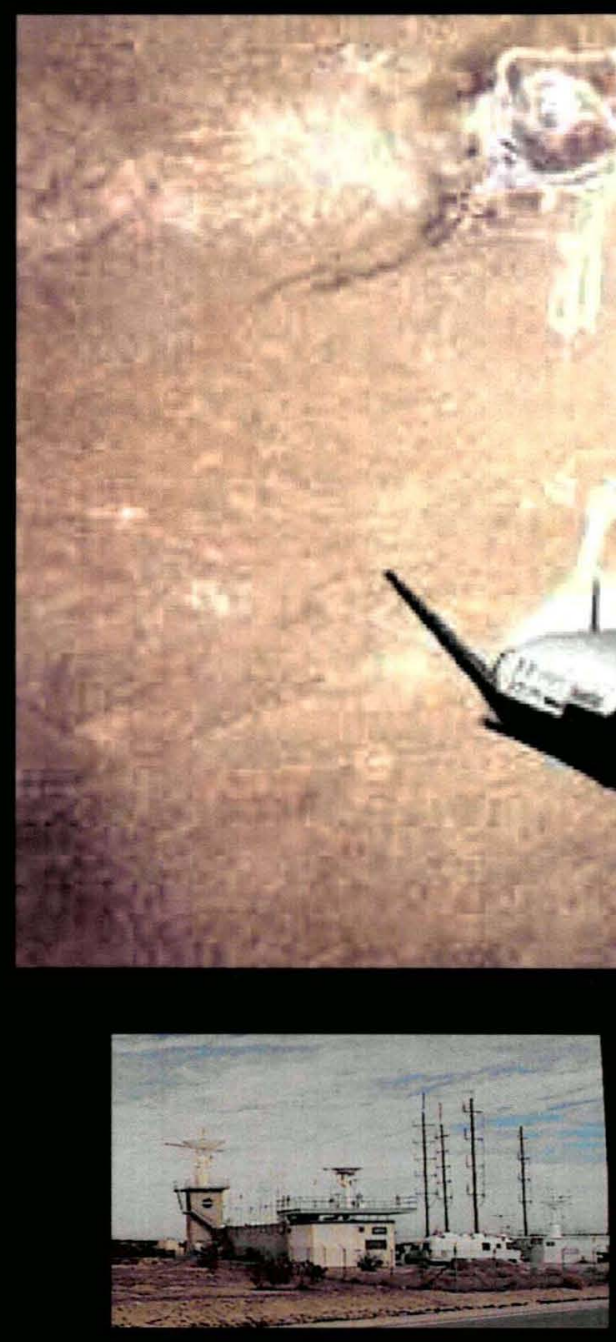

Flight Termination DFRC 16', $1 \mathrm{KW}$

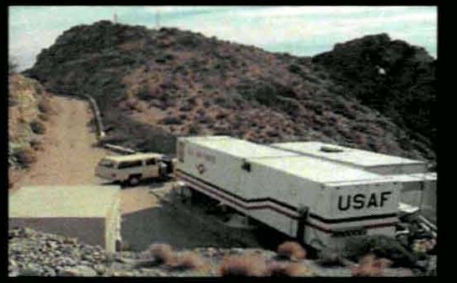

Leuhman Ridge 200W omni L-band Uplink

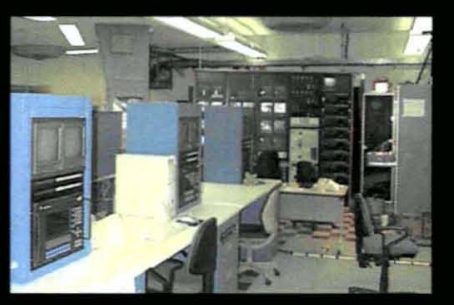

Flight Ops Center OCC location

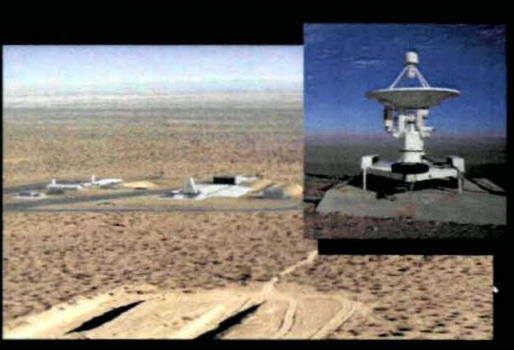

Shadow Mountain AFFTC 8' TM S-Band downlink
NASA Comm

Range Nets

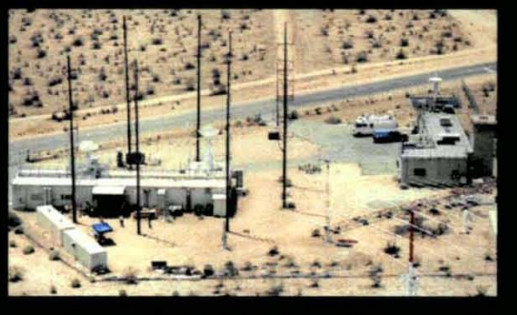




\section{Range - Landing Site \#1 Support}

\section{Dugway Proving Grounds, UT}

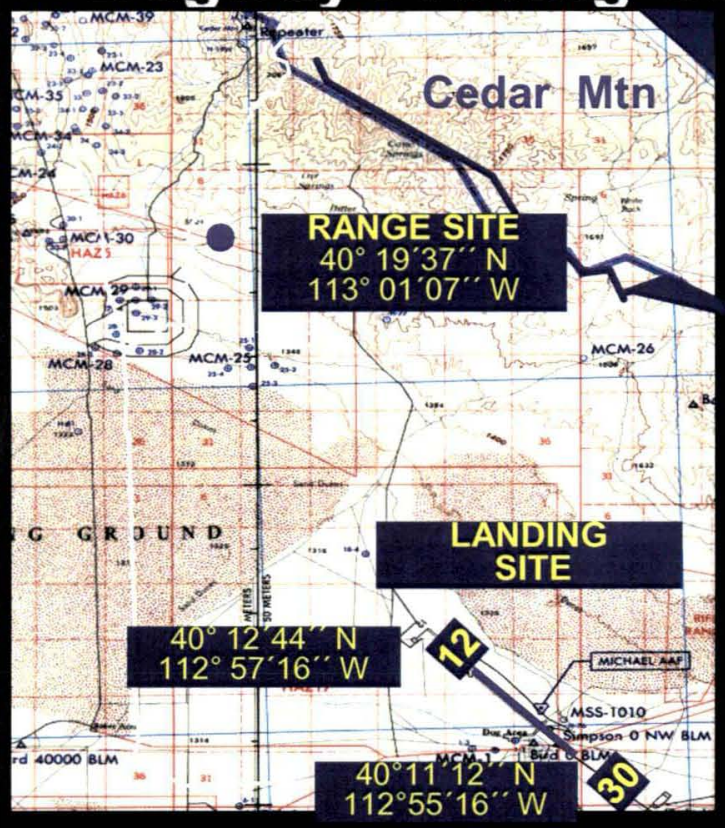

- NASA ER-2 test flights validate extended test range between Edwards AFB and Dugway, Sept. 1999
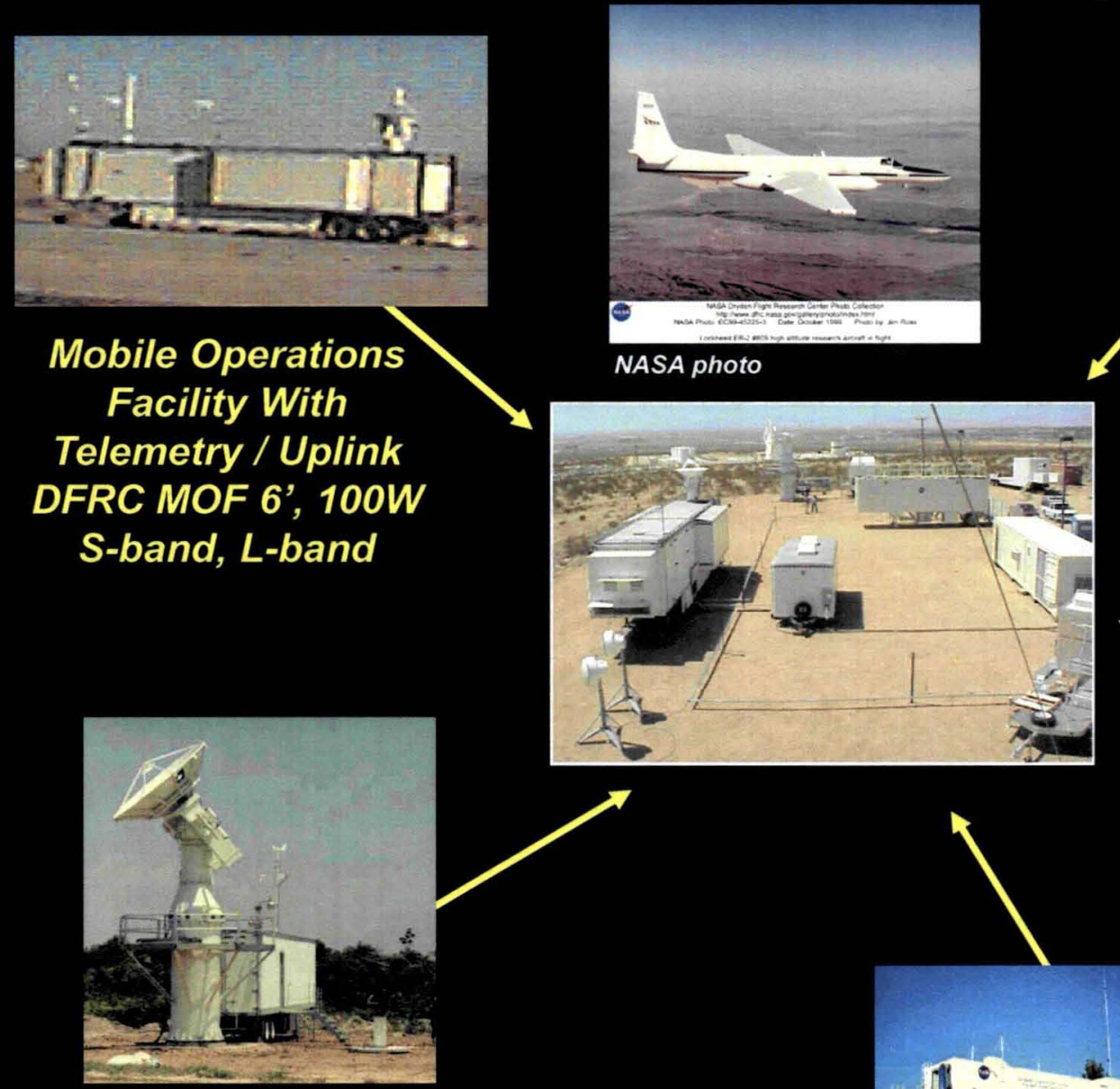

Redundant Radar Wallops Mobile Radar \#11, 12', 1MW UTTR TPQ-39 Radar, 12', 1MW

S-band, L-band

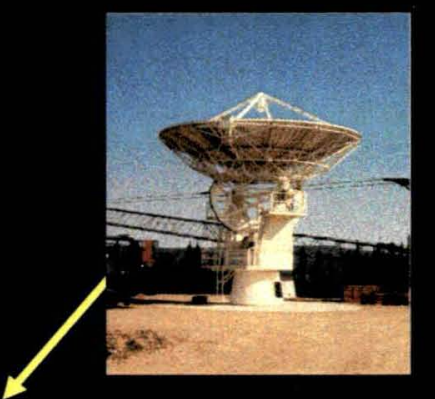

Telemetry / Uplink DFRC 9m, 200W S-band, L-band

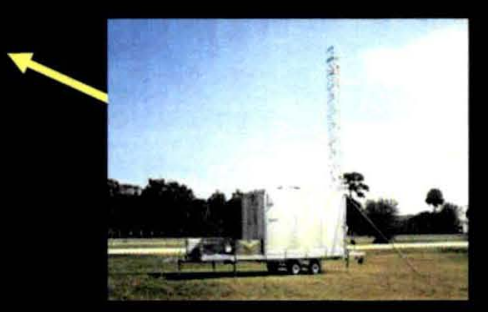

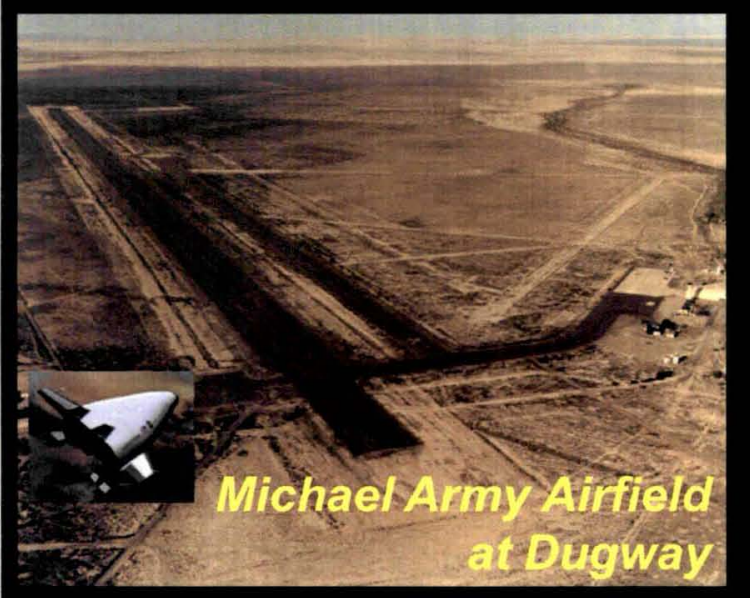
at Dugway

Microwave

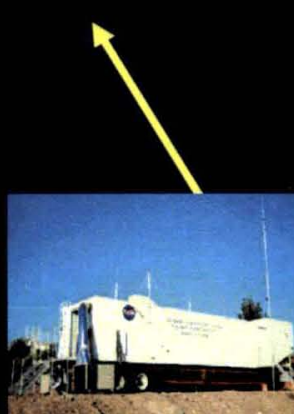

Redundant FTS Wallops CTS \#1, $1 \mathrm{KW}$ dual helix 


\section{Range - Landing Site \#2 Support}

\section{Malmstrom AFB, Montana}

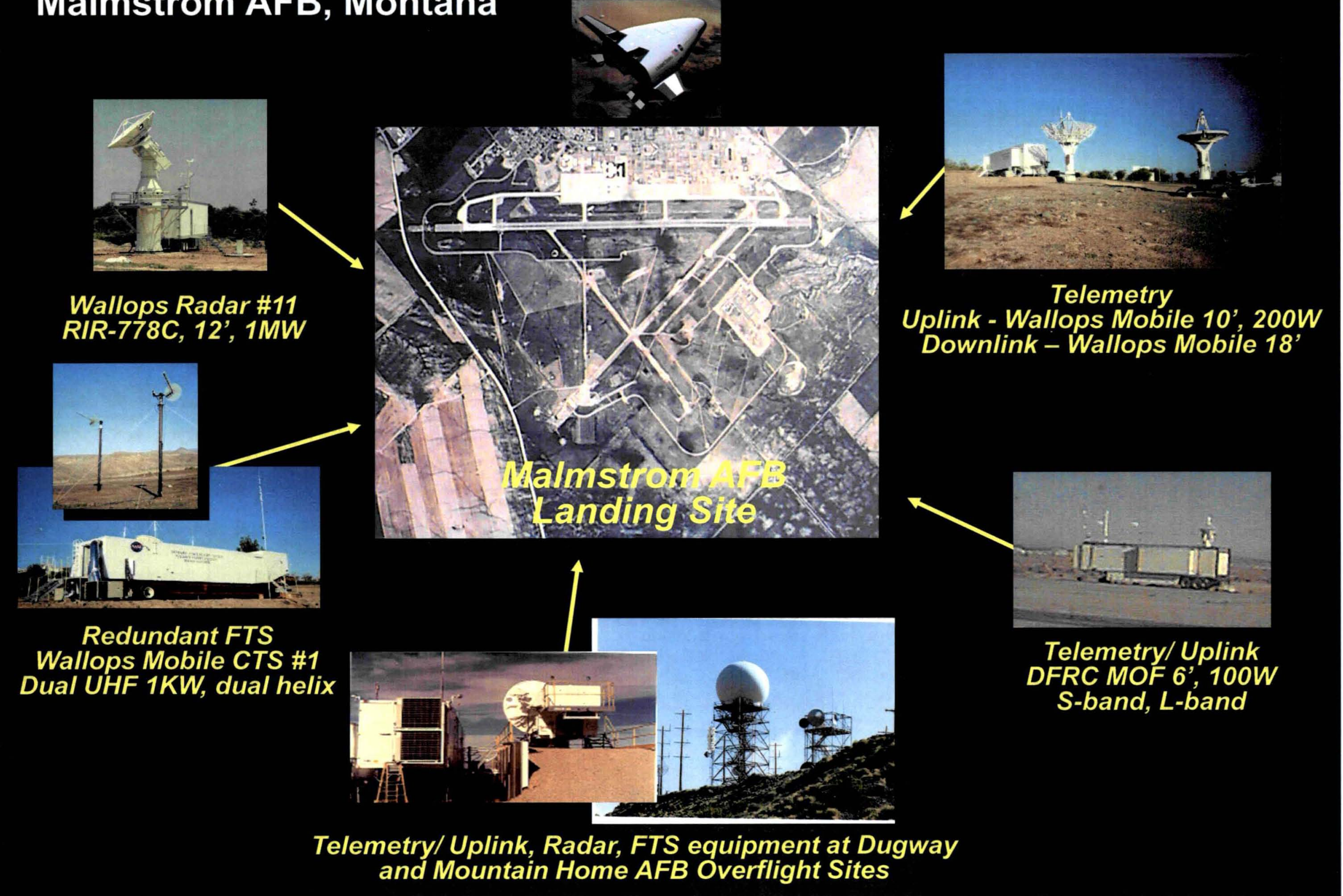




\section{Single Stage to Orbit (VentureStar ${ }^{\mathrm{T}}$ ) Development}

- Continuous vehicle design optimization, based on X-33 lessons

- System Requirements Review completed, March 1998

- System Architecture Review / Optimized Design Review completed, July 1998

- JSC 28354 Human Rating Requirements evaluation reviewed with NASA, Oct 1998

- NASA/LM ISS Visiting Vehicle Interface Meeting, Feb 1999

- NASA ISS Crew Module Phase A Study, Aug 1999

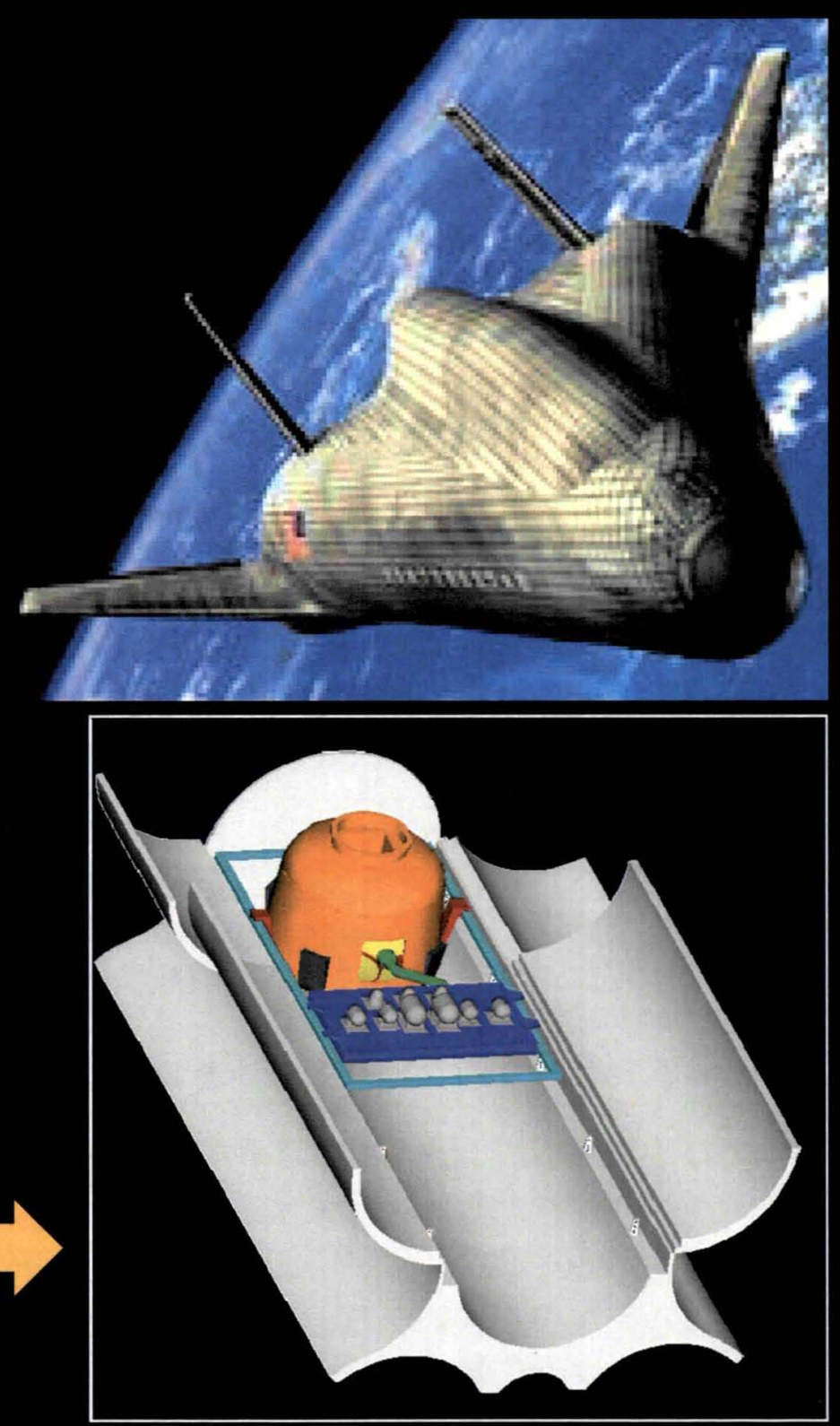




\section{Technical Lessons Learned}

- SSTO vehicle design optimized based on X-33 structural, aero, propulsion and conops maturation, and future payload customer inputs

- SSTO concept improvement examples from X-33 demonstrator:

- Uniform TPS interface to airframe

- TPS support structure optimized for manufacturing and installation

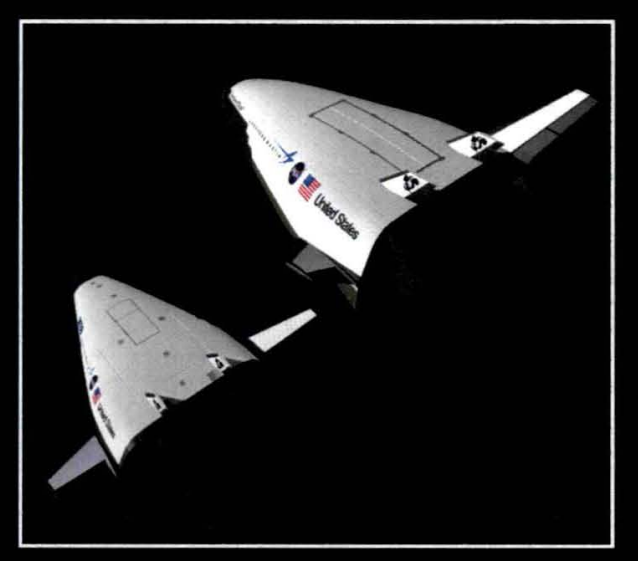

- Extended use temperature for FRSI and AFRSI thermal insulation

- Aerospike engine layout and load path integration with vehicle

- Mission module structural interface to vehicle

- Propellant packing efficiency and tank design

- Graphite epoxy composite structure

- Aerosurface design

- Other lessons learned from X-33:

- Rapid Environmental Impact Statement development and approval

- Optimization of launch site selection

- Streamlined range safety tailoring and flight approval

- Simplify abort modes to streamline flight planning, software and IV\&V

- Small expert teams with focused tasks and aggressive goals are highly productive 


\section{Programmatic Challenges}

- "Faster, better, cheaper" in 1996; risk aversion by 2001

- High technical and economic expectations for a demonstrator

- New technologies

- Rapid operational turnaround

- Demanding development schedule

- Highly constrained budget

- Little margin for covering development problems

- NASA, DOD, Commercial NOAA payload stakeholders

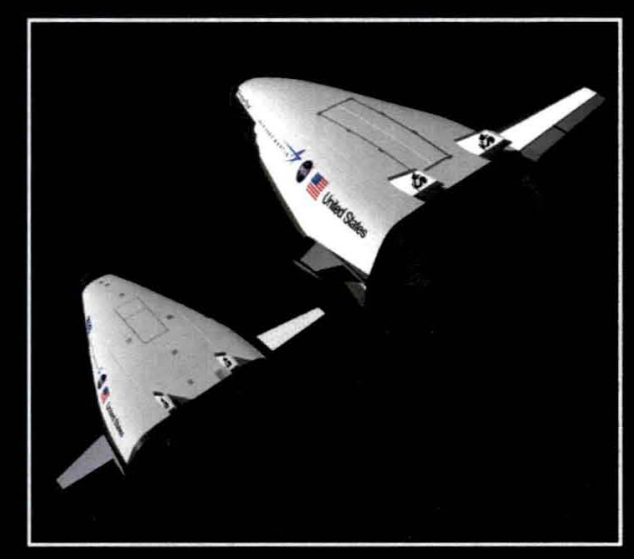

- NASA, White House, DOD, Congress, Corporate political stakeholders

- Payload markets: LEO, MEO, GTO, Humans and Cargo to ISS

- X-33 Team changes in management and program priority

- Lockheed merges with Martin Marietta and becomes Lockheed Martin

- Rocketdyne-Rockwell becomes Rocketdyne-Boeing

- Rohr merges with BF Goodrich

- Allied Signal merges with Honeywell

- Space launch market downturn in forecasted LEO satellites

- Funding challenges from LH2 tank issues and engine development 


\section{Programmatic Lessons Learned}

- Program was trying to accomplish too much with inadequate cost and schedule margin

- Stakeholders expected X-33 to perform the function of an $X$-vehicle (technology risk reduction) and a Y-vehicle (cost risk reduction)

- Technology demonstrators require margin and "risk off-ramp" for known high risk items (i.e., LH2 composite tank)

- Only accept critical technologies, too many creates unacceptably high risk

- Program and stakeholders agree on acceptable technical and cost risk levels

- US Government focus on low cost, versus investor high cash flow

- Risk level may vary with investment contribution

- Be flexible on balancing competing requirements, or focus on a subset of stakeholders and their market objectives

- Program partners shoulder comparable risks or become subcontractor

- Objective "new product investment" economic analysis when commercial use is essential part of business plan

- Management structure should remain flexible for changes in economic and political environment over time 


\section{Programmatic Lessons Learned, cont.}

- US Government's unconventional cooperative agreement procurement tool allowed flexibility

- Shared investment and risk

- Streamlined management

- Small US Government program office

- Government insight focus, versus oversight

- SSTO concepts for lowering cost of space access are still valid

- Reuse high-value hardware

- Reduce labor intensive tasks

- Increase reliability by minimizing staging events and designing for engine-out capability

- Costs interdependent with launch rate

- NASA funded X-vehicle efforts should be better communicated to the public and industry

- Current and future space launch developers and stakeholders can benefit from the knowledge gained 


\section{X-33 Program Summary}
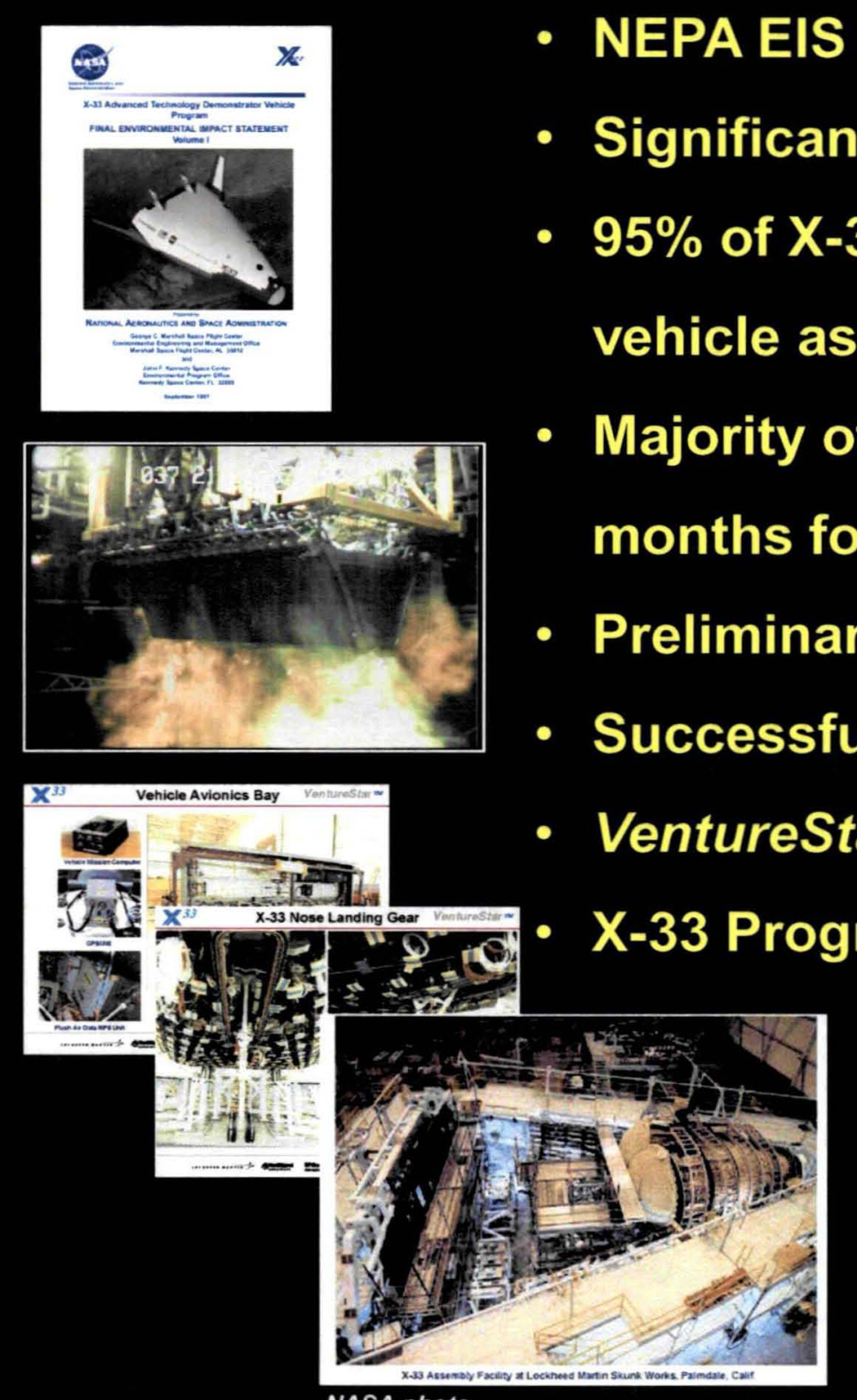

NASA photo
- NEPA EIS approval process successful in only 14 months

- Significant level of engine testing completed

- $95 \%$ of X-33 components fabricated, tested and delivered, vehicle assembly $75 \%$ complete, as of Sept. 2000

- Majority of Flight Operations Center constructed in 12 months for $\$ 32 M$

- Preliminary Flight Plan Approval achieved

- Successfully tested Extended Test Range for Dugway flights

- VentureStar ${ }^{T M}$ SRR and SAR Reviews complete by July 1998 - X-33 Program Cooperative Agreement completed, Mar. 2001

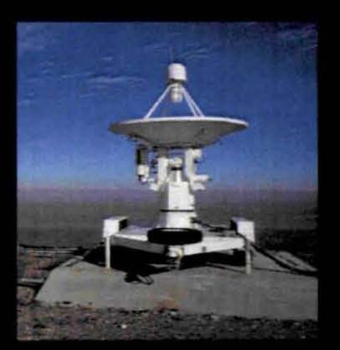




\section{For More X-33 History}

http://www.hq.nasa.gov/office/pao/History/x-33/menu_time.htm

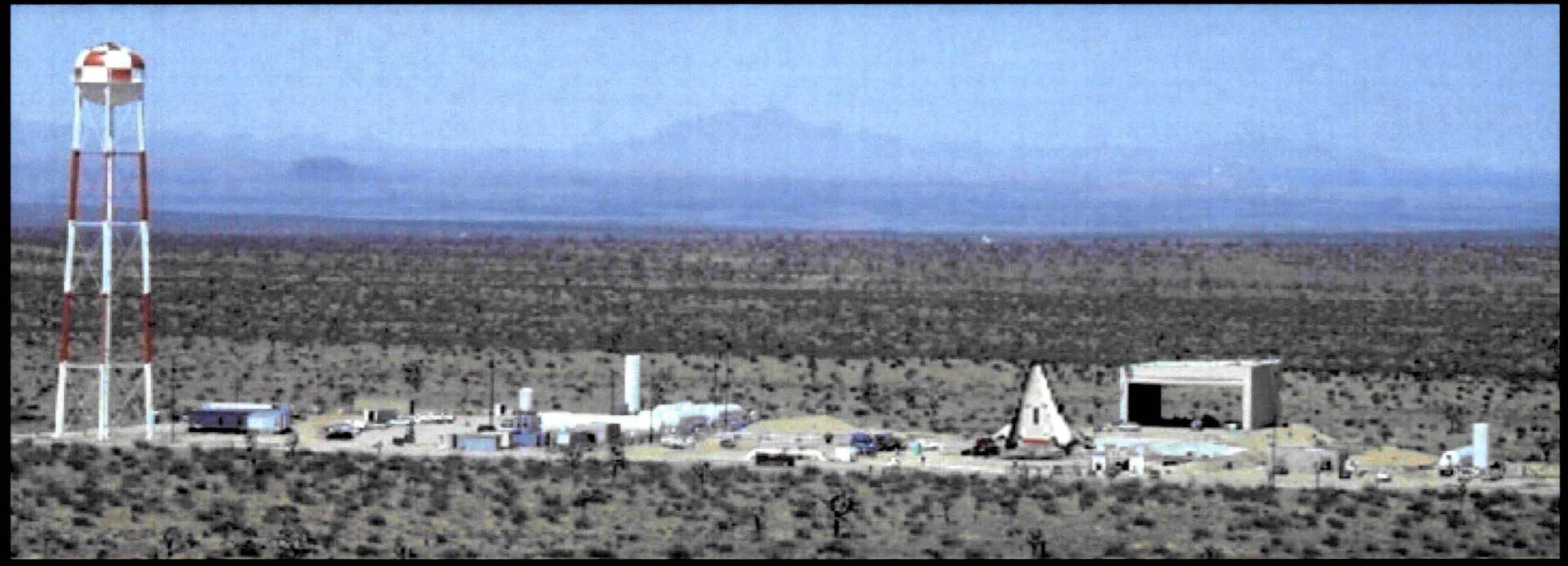

"X-vehicle programs are about taking risks and pushing the envelope. That is how we break through barriers that previously held us back."

- Gene Austin, X-33 NASA Program Manager 